\title{
Health Problems of Affluent Societies
}

The health conditions reviewed in this chapter are to some extent characteristic of 'affluent' societies, but this is only true up to a certain point: many of these diseases first rose with rising prosperity in the 2oth century, but then started to decline in the second half of the century, despite the fact that prosperity continued to rise. Within high-income societies, they then became concentrated in lower socioeconomic groups, and thus in a sense turned into diseases of poverty. Nevertheless, their rise was in many cases a side-effect of rapid economic growth, which is why we present their secular trends under this heading.

\section{Chronic Diseases}

Diseases of the cardiovascular system have spectacularly risen, and then spectacularly declined again, during the 2oth century. This was not only a matter of filling the space left by infectious diseases - when people no longer died from infectious diseases, they lived longer, but ultimately had to die from something else - but the rates of cardiovascular disease also increased in real terms in many European countries.

This can clearly be seen in the available mortality data, which for many countries go back to the beginning of the 2oth century: not only did the proportion of all deaths attributed to cardiovascular disease increase and then decline again (see Suppl. Figure 5), but absolute levels of cardiovascular disease also first rose and then declined, often dramatically, even after removing the effects of an ageing population. This pattern of 'rise-and-fall' was by no means unique to Europe, but reflects a global phenomenon: with socioeconomic development, mortality from cardiovascular diseases first rises but then declines again. ${ }^{1}$

1 For a world-wide analysis of the association between 'sociodemographic development' and mortality from cardiovascular disease in the period 1990-2015, see Gregory A. Roth et al., "Global, Regional, and National Burden of Cardiovascular Diseases for 10 Causes, 1990 to 2015," Journal of the American College of Cardiology 70, no. 1 (2017): 1-25. 


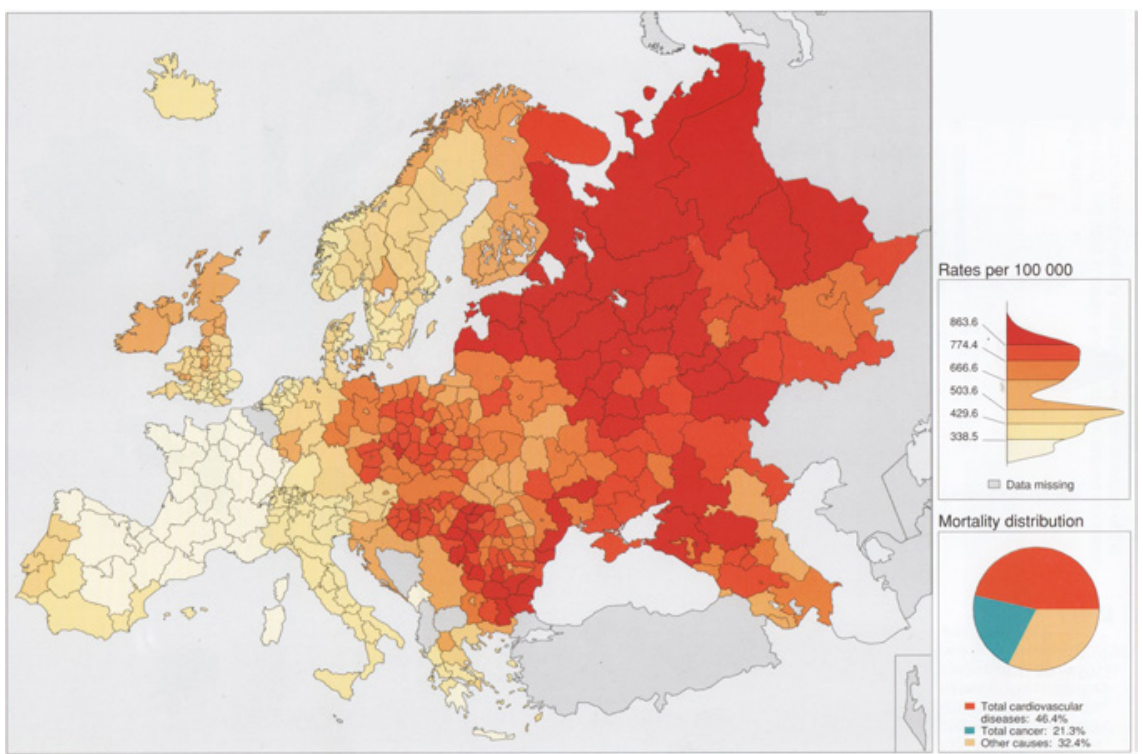

PLATE 14 Map of cardiovascular disease mortality in Europe, 1990

This map shows mortality from cardiovascular diseases by subnational region in almost all European countries, even including a large part of European Russia. Only Belgium (!), Bosnia, Albania, North Macedonia and Turkey were unable to contribute data to the Atlas from which this plate has been reproduced. What we see is dominated by a striking West-East gradient, with generally lower mortality in the West of Europe and higher mortality in the East. National boundaries often produce sharp contrasts in mortality rates, as in the case of Portugal vs. Spain, Germany and Austria vs. Czech Republic and Hungary, and Finland vs. Russia.

WORLD HEALTH ORGANIZATION, ATLAS OF MORTALITY IN EUROPE. SUBNATIONAL PATTERNS, 1980/1981 AND 1990/1991 (COPENHAGEN: WHO EUROPE, 1997), PAGE 77. REPRODUCED WITH PERMISSION

Hiding below these over-all trends, however, are very different trends for the specific diseases that make up the broader group of 'cardiovascular disease'. It includes various forms of heart disease (such as congenital heart disease, chronic rheumatic heart disease, and ischaemic heart disease), cerebrovascular disease, hypertensive disease, aortic aneurysm and many other conditions, all of which have followed their own long-term trends. Thanks to an abundance of epidemiological studies we are relatively well informed about trends and variations in cardiovascular disease (Plate 14). This section will focus on the two diseases that for most of the 2oth century have been the most important: ischaemic heart disease and cerebrovascular disease. ${ }^{2}$

2 Currently, more than half of all deaths from cardiovascular disease in Europe are due to ischaemic heart disease, and between one-quarter and one-third to cerebrovascular disease; see Roth et al., "Global, Regional, and National Burden of Cardiovascular Diseases", fig. 4. 


\section{Ischaemic Heart Disease}

'Ischaemic heart disease' is a disease that has only relatively recently been recognized as a separate disease entity, probably because it was rare before the end of the 19th century. Its current name (as well as synonyms like 'arteriosclerotic heart disease' and 'coronary heart disease') refers to the underlying disease process, i.e., atherosclerosis of the coronary arteries that provide the heart muscle with oxygen. Restriction of the blood flow to the heart muscle may lead to pain during physical exertion (angina pectoris). When combined with coronary thrombosis, as happens when an atherosclerotic plaque ruptures, it may lead to a potentially fatal myocardial infarction. ${ }^{3}$

This understanding of the link between symptoms and underlying disease process has developed slowly between the 1880 s and 1920s. This also implies that some of the rise of ischaemic heart disease in the first half of the zoth century probably reflects better recognition. The first clear descriptions of the then still puzzling - symptoms of angina pectoris date back to the 18th century. The idea that the acute event of what we now call a 'myocardial infarction' was caused by occlusion of the coronary arteries emerged in the last decades of the 19th century, and remained disputed well into the 2oth century. ${ }^{4}$

The underlying disease process - atherosclerosis of the coronary arteries begins early in life, and autopsy studies have shown that the prevalence was already high in several European countries in the first half of the 2oth century. These studies also showed that the prevalence temporarily declined during World Wars I and II, suggesting a link between atherosclerosis of the coronary arteries and the abundance or shortage of food. ${ }^{5}$

The rise of ischaemic heart disease led to huge investments in research, particularly in the United States where this 'epidemic' occurred somewhat earlier than in Europe. Research findings have confirmed an important role for dietary

3 See Christian Weber and Heidi Noels, "Atherosclerosis: Current Pathogenesis and Therapeutic Options," Nature Medicine 17, no. 11 (2011): 1410-422 for an overview of the current understanding of the pathogenesis of ischaemic heart disease.

4 The first clear description of the suspected link between coronary occlusion and sudden death was given in 1878 , and Osler's textbook The principles and practice of medicine (1892) briefly referred to what we would now call a myocardial infarction. For the history of the understanding of this disease, see David S. Jones, Broken Hearts (Baltimore: Johns Hopkins University Press, 2013); W. Bruce Fye, "The Delayed Diagnosis of Myocardial Infarction: It Took Half a Century!," Circulation 72, no. 2 (1985): 262-71.

5 Autopsy trend studies of atherosclerosis in Northern and Western Europe and in the US were summarized in Henschen, History, pp. 217-24. A high prevalence of atherosclerosis of the coronary arteries in the first decades of the 2oth century, and a lower prevalence in the immediate post-World War II years, was found in an autopsy study from London; see Jerry N. Morris, "Recent History of Coronary Disease," Lancet 257, no. 6645 (1951): 1-7. 
factors as well as for a number of other risk factors in the aetiology of this disease. The list of established risk factors is quite long. The three most important risk factors are high serum cholesterol, cigarette smoking, and high blood pressure, but diabetes, obesity, lack of physical exercise, low fruit \& vegetable consumption, excessive alcohol consumption, depression, job stress, adverse childhood conditions, and genetics also increase the risk of ischaemic heart disease.

This has provided ample opportunities for prevention of ischaemic heart disease, for example by reducing high serum cholesterol (through dietary modification or cholesterol-lowering drugs (statins)), by reducing hypertension (through case finding and treatment with antihypertensive drugs), and by reducing smoking (through smoking cessation advice and support). This has gradually evolved into the adoption of systematic 'cardiovascular disease risk management' by medical professionals, and a growing recognition that this needs to be supported by society-wide measures to reduce saturated fat, trans fatty acids and salt content of foods, to discourage tobacco consumption, and to promote physical exercise.

The growing understanding of the pathogenetic mechanisms underlying ischaemic heart disease has also created ample opportunities for life-saving treatment, both immediately after the acute event of a myocardial infarction and during later stages of the disease. Coronary care units, introduced in the 1970s, were probably not effective in lowering mortality, but thrombolytic therapy and revascularization of the coronary arteries are life-saving. The latter intervention may involve 'coronary artery bypass grafting', or the simpler 'percutaneous coronary intervention' in which a stent is used to re-open an occluded artery. Treatment of the acute event needs to be followed by 'secondary prevention' through similar strategies of risk factor modification as in primary prevention: lifestyle changes, statins, antihypertensive drugs, anticoagulation drugs, ...6

Trends in ischaemic heart disease mortality in Europe are shown in Figure 22. The country with the longest times-series is England \& Wales, where mortality

6 For an overview of the relative importance of the classical risk factors for ischaemic heart disease, see Peter W.F. Wilson et al., "Prediction of Coronary Heart Disease Using Risk Factor Categories," Circulation 97, no. 18 (1998): 1837-847. For the effectiveness of secondary prevention, see Finlay A. McAlister et al., "Randomised Trials of Secondary Prevention Programmes in Coronary Heart Disease," British Medical Journal 323, no. 7319 (2001): 957-62. 
Ischaemic heart disease, men 800

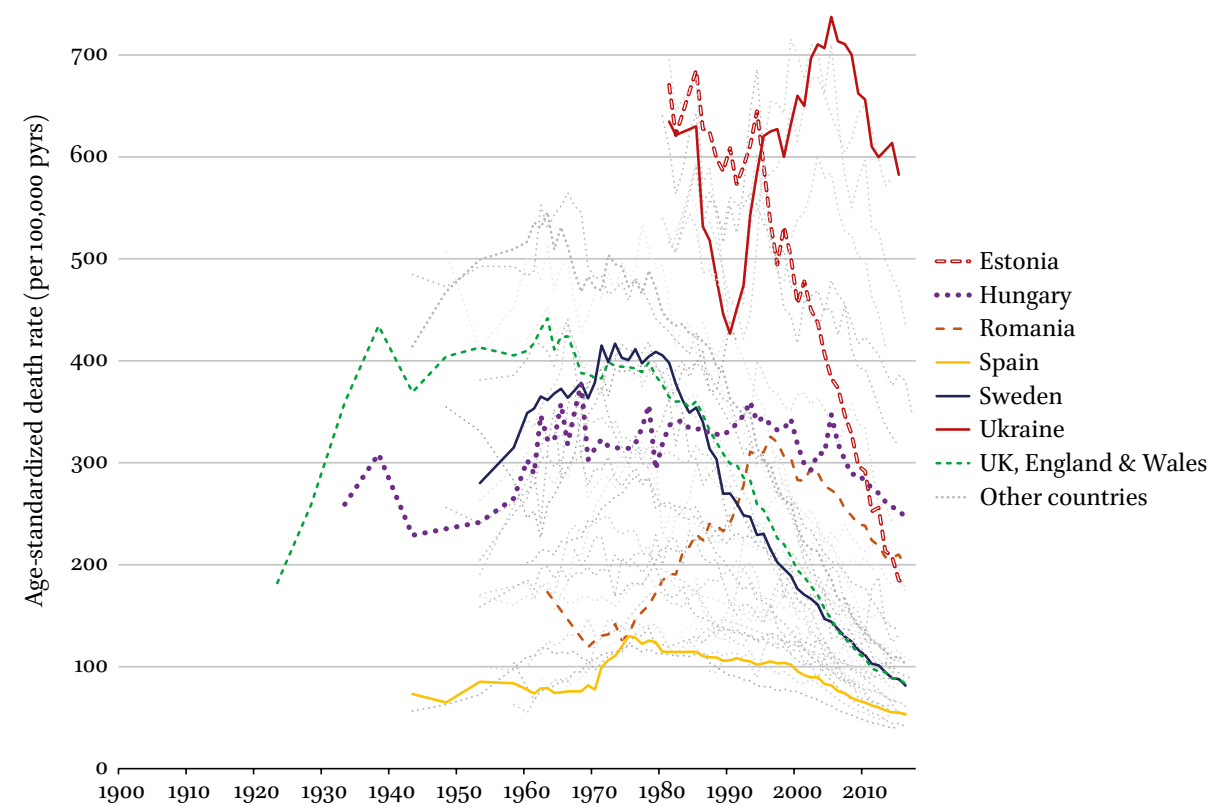

FIGURE 22 Trends in ischaemic heart disease mortality in Europe, 1900-2015

Notes: Quinquennial data before 1960

SOURCE OF DATA: SEE SUPPL. TABLE 1

from ischaemic heart disease can be followed from the 1920s onwards. It shows a rapid rise until the mid-1970s, and a continuous decline thereafter. ${ }^{7}$

Many other European countries also show a clear 'rise-and-fall' pattern, but with important differences in both timing of the peak and level of mortality

7 The rapid rise of ischaemic heart disease mortality in England \& Wales in the first half of the 2oth century has been well documented, even over a longer period than shown in Figure 22; see Maurice Campbell, "Death Rate from Diseases of the Heart: 1876 to 1959," British Medical Journal 2, no. $535^{6}$ (1963): 528-35. Time-series of autopsies in London hospitals between 1868 and 1982 also show an increasing prevalence of ischaemic heart disease at death; see Rodney Finlayson, "Ischaemic Heart Disease, Aortic Aneurysms, and Atherosclerosis in the City of London, 1868-1982," Medical History 29, no. S5 (1985): 151-68. The temporary decline seen during World War II (Figure 22) may be a coding artefact; see David J. Barker and C. Osmond, "Diet and Coronary Heart Disease in England and Wales During and after the Second World War," Journal of Epidemiology \& Community Health 40, no. 1 (1986): 37-44. 
reached during the peak. In many Northern and Western European countries, ischaemic heart disease mortality peaked somewhat later than in England \& Wales, but at similar levels. However, in Southern Europe mortality peaked at much lower levels, whereas ischaemic heart disease mortality in Eastern Europe appears to have followed a 'saw-tooth' trajectory with repeated peaks in the 1980s, 1990s and early 2000s. Despite recent rapid declines, Russia, Ukraine and other countries of the former Soviet Union have the world's highest rates of ischaemic heart disease mortality. 8

The breath-taking decline of ischaemic heart disease mortality has generated an enormous literature. In the US, the decline started somewhat earlier than in Europe, in the mid-196os, but at first went unnoticed, and it took quite some time before a certain degree of consensus on the causes of the decline emerged. Even now, 50 years later, the explanation of the decline of ischaemic heart disease mortality throughout the developed world is still somewhat tentative. This is paradoxical because our understanding of the determinants of ischaemic heart disease is much better than that of most other diseases, and because the availability of data on trends in risk factors and treatment patterns is also much more extensive. ${ }^{9}$

Clearly, to explain these trends we need to distinguish between trends in incidence and survival of ischaemic heart disease, but it is important to realize that risk factor trends can influence both incidence and survival, and that medical care does not only influence survival but can also reduce risk factor exposure, for example by lowering serum cholesterol or blood pressure.

The rise of ischaemic heart disease mortality must have been due to a rise in incidence, because there is little reason to suspect a rise in case fatality. Although data on risk factor exposure before the 196os are very limited, it is likely that the rise in incidence in Northern and Western European countries was

8 An analysis of the timing of the peaks in ischaemic heart disease mortality can be found in Masoud Mirzaei et al., "Coronary Heart Disease Epidemics: Not All the Same," Heart 95, no. 9 (2009): 740-46. For a comparison between ischaemic heart disease mortality levels in different world regions, see Andrew E. Moran et al., "Temporal Trends in Ischemic Heart Disease Mortality in 21 World Regions, 1980 to 2010," Circulation 129, no. 14 (2014): 1483-492.

9 Although the decline of ischaemic heart disease mortality in the US followed improvements in prevention and treatment, the famous Bethesda conference, held in 1978, could not reach conclusions about its causes. It was only later, with the use of quantitative models, that a clearer picture emerged; see David S. Jones and Jeremy A. Greene, "The Contributions of Prevention and Treatment to the Decline in Cardiovascular Mortality," Health Affairs 31, no. 10 (2012): $2250-258$. The role of risk factor trends and medical care in the decline of cardiovascular disease mortality has been reviewed in Majid Ezzati et al., "Contributions of Risk Factors and Medical Care to Cardiovascular Mortality Trends," Nature Reviews Cardiology 12, no. 9 (2015): 508-30. 
due to the adoption of an 'affluent' diet rich in saturated fats, to the adoption of a more sedentary way-of-life, and to the rise of cigarette smoking. These changes in risk factor exposure were less strong in Southern Europe, and were compounded by periods of rises-and-falls in excessive alcohol consumption in Eastern Europe, which probably explains some of the regional differences seen in Figure 22.

Because it occurred more recently, we are better informed about factors that may have contributed to the decline of ischaemic heart disease mortality. The MONICA study - set up to provide internationally comparable data on ischaemic heart disease incidence, case fatality, mortality and risk factors - showed that between the mid-1980s and mid-199os declining mortality was the result of both declining incidence and declining case fatality. On average, across the 21 participating countries (many of which are in Europe), declines in incidence contributed two-thirds of the declines in mortality, whereas declines in case fatality contributed one-third. ${ }^{10}$

These declines in incidence and case fatality were due to a combination of favourable risk factor changes, as a result of health promotion programs and cardiovascular risk management, and improvements in medical care. The MONICA study, as well as many national studies, have shown that in many European countries population-level trends in serum cholesterol, smoking (unfortunately, among men only), and blood pressure have been favourable. On the other hand, trends in obesity and smoking among women have been unfavourable, but quantitative analyses have shown that trends in risk factors can indeed partly explain trends in ischaemic heart disease incidence and/or mortality.11

On the other hand, improvements in treatment have contributed as well. In-hospital case fatality has declined impressively, probably due to advances in acute care, and in the MONICA study declines in case fatality have been

$10 \quad$ Hugh Tunstall-Pedoe et al., "Contribution of Trends in Survival and Coronary Event Rates to Changes in Coronary Heart Disease Mortality," Lancet 353, no. 9164 (1999): 1547-557. Many national studies have been conducted, showing that the relative contribution of incidence and case fatality to mortality decline differed between time-periods and between countries (Ezzati et al., "Contributions").

11 For the results of the MONICA study, see Alun Evans et al., "Trends in Coronary Risk Factors in the wHo MONICA Project," International Journal of Epidemiology 30, no. Supplement 1 (2001): S35-S40. More recently, the European Society of Cardiology has compiled and analysed population-based data on ischaemic heart disease and its risk factors; see Adam Timmis et al., "European Society of Cardiology: Cardiovascular Disease Statistics 2017," European Heart Journal 39, no. 7 (2017): 508-79. Reduced salt consumption may have contributed to lower blood pressure (Ezzati et al., "Contributions"). 
strongest in European countries - usually in the Northern and Western part of the region - where the improvements in treatment were strongest. ${ }^{12}$

In general, studies have found that, although improvements in treatment have made important contributions, risk factor changes have contributed more to declines in ischaemic heart disease mortality. Risk factor changes were, however, partly the result of risk factor management within the health care system, so that both medical care and public health can rightly claim to have played an important role in the decline of ischaemic heart disease. ${ }^{13}$

In Chapter 7 , we discuss why these trends played out so differently in different European countries.

\section{Cerebrovascular Disease}

Cerebrovascular disease is a disease of the brain which is characterized by a sudden and often dramatic failure of neurologic functions, such as paralysis of parts of the body, inability to speak, or loss of consciousness. This frightening event is commonly called 'stroke', and as the official name indicates, it is caused by a problem of the blood vessels of the brain. It occurs in two main forms: 'haemorrhagic stroke' (due to rupture of the wall of a blood vessel, resulting in a blood clot pressing against brain tissue) and 'ischaemic stroke' (due to occlusion of a blood vessel leading to insufficient perfusion of brain tissue). Both forms of cerebrovascular disease have a high case fatality, and when people survive they often suffer from severe disabilities. Currently, ischaemic stroke is more frequent than haemorrhagic stroke, but the reverse was true a century

12 The MONICA study showed that about half of the variation in survival trends was explained by treatment - with more improvement in Western than in Eastern Europe; see Hugh Tunstall-Pedoe et al., "Estimation of Contribution of Changes in Coronary Care to Improving Survival, Event Rates, and Coronary Heart Disease Mortality," Lancet 355, no. 9205 (2000): 688-700.

13 The contribution of risk factor changes has been documented both in studies relating population-level trends in risk factors to trends in ischaemic heart disease (Kari Kuulasmaa et al., "Estimation of Contribution of Changes in Classic Risk Factors to Trends in Coronary-Event Rates," Lancet 355, no. 9205 (2000): 675-87), and in simulation studies using individual-level data (Tiina Laatikainen et al., "Explaining the Decline in Coronary Heart Disease Mortality in Finland between 1982 and 1997," American Journal of Epidemiology 162, no. 8 (2005): 764-73; Belgin Unal, Julia Alison Critchley, and Simon Capewell, "Explaining the Decline in Coronary Heart Disease Mortality in England and Wales between 1981 and 2000," Circulation 109, no. 9 (2004): 1101-107). The contributions of risk factor changes and improvements in prevention and treatment may well have differed between time-periods and countries; see Earl S. Ford and Simon Capewell, "Proportion of the Decline in Cardiovascular Mortality Disease Due to Prevention Versus Treatment," Annual Review of Public Health $3^{2}$ (2011): 5-22. 
ago, because since then haemorrhagic stroke has declined much more than ischaemic stroke. ${ }^{14}$

The risk factors for cerebrovascular disease have been studied extensively, and are relatively well-known. Hypertension, risk factor number 1, is extremely common: the prevalence of hypertension in European countries typically ranges between 30 and $60 \%$ of the adult population. It generally increases with socioeconomic development, probably due to the changes in diet and behaviour that accompany industrialization and urbanization. Hypertension may be due to high salt consumption, low fruits and vegetables consumption, low physical exercise, obesity, excessive alcohol consumption, and/or psychosocial stress, and many of these conditions have become more common during socioeconomic modernization. ${ }^{15}$

Hypertension increases the risk of both types of stroke, but a higher proportion of cases of haemorrhagic stroke is attributable to hypertension, because ischaemic stroke has other important risk factors as well, such as high serum cholesterol and smoking. As hypertension rises with socioeconomic development, the frequency of haemorrhagic stroke may also have risen before starting its 2oth century decline, but we have no quantitative data to test this idea. ${ }^{16}$

14 This is due to the fact that haemorrhagic stroke has declined more than ischaemic stroke; see Mark O. McCarron, George Davey Smith, and P. McCarron, "Secular Stroke Trends: Early Life Factors and Future Prospects," Quarterly Journal of Medicine 99, no. 2 (2006): 117-22.

15 Although there are no historical data on the prevalence of hypertension, circumstantial evidence suggests a rise of hypertension with socioeconomic development. Hypertension is very rare in hunter-gatherers (Trowell and Burkitt, Western Diseases), and the Global Burden of Disease study shows that currently the prevalence of hypertension is higher in a number of middle-income countries than in both low- and high-income countries, suggesting an inverted-U-shaped relationship (Mohammad H. Forouzanfar et al., "Global Burden of Hypertension and Systolic Blood Pressure of at Least 110 to $115 \mathrm{Mm} \mathrm{Hg}$, 19902015," Journal of the American Medical Association 317, no. 2 (2017): 165-82). Estimates of the current prevalence of hypertension in European countries can be found in, e.g., Goodarz Danaei et al., "National, Regional, and Global Trends in Systolic Blood Pressure since 1980," Lancet 377, no. 9765 (2011): 568-77.

16 Evidence for a rise of haemorrhagic stroke is circumstantial only. The Global Burden of Disease study shows that the incidence of haemorrhagic stroke is higher in middle-income than in high-income countries, which is compatible with the inverted-U-shaped relationship inferred for hypertension; see Valery L. Feigin et al., "Worldwide Stroke Incidence and Early Case Fatality Reported in 56 Population-Based Studies," Lancet Neurology 8 , no. 4 (2009): $355^{-69}$. The high frequency with which medical treatises on 'apoplexy' the term under which the disease was known in the past - were published in the 18th century suggests that by then it had become more common; see Pandora Pound, Michael Bury, and Shah Ebrahim, "From Apoplexy to Stroke," Age and Ageing 26, no. 5 (1997): $33^{1-37}$. 
Hypertension is a silent killer, because it is usually symptomless and can only be discovered if it is measured using a sphygmomanometer. Before the 196os hypertension could not be treated, but in the 196os the first modern drugs for the treatment of hypertension, thiazide diuretics, were introduced. In the 1970 s these were followed by beta blockers, and in the 1980 s by a whole series of other drugs. Antihypertensive drugs have been shown to not only lower blood pressure, but also to lower the risk of cerebrovascular disease (as well as other complications of hypertension, such as ischaemic heart disease) ${ }^{17}$

As soon as hypertension became amenable to medical intervention, systematic detection of hypertension in otherwise healthy people became a useful thing to do, and recommendations to routinely measure blood pressure in patients consulting their doctors for other reasons, gradually came to be included in clinical practice guidelines around the Western world. However, carrying out these guidelines is far from trivial, and adoption therefore is still incomplete in even the most advanced countries.

Coverage of all people who might have hypertension without knowing it, can only be achieved in primary care. However, notall countries have well-organized primary care services, and even when they have, primary care physicians have not always been willing to incorporate this in their everyday work. Furthermore, antihypertensive drugs need to be available to patients without financial barriers, and patients need to comply with their doctors' advice to take their drugs, sometimes life-long and even if they have side-effects - conditions that haven proven difficult to fulfil. Nevertheless, there has been a gradual increase of the proportion of hypertensives under control, particularly in Northern and Western Europe. ${ }^{18}$

17 Blood Pressure Lowering Treatment Trialists' Collaboration, "Effects of Different BloodPressure-Lowering Regimens on Major Cardiovascular Events," Lancet 362, no. 9395 (2003): 1527-535; Vijaya M. Musini et al., "Pharmacotherapy for Hypertension in the Elderly," Cochrane Database of Systematic Reviews, no. 4 (2009): CDoooo28.

18 For organizational requirements and role of primary care, see, e.g., Liam G. Glynn et al., "Interventions Used to Improve Control of Blood Pressure in Patients with Hypertension," Cochrane Database of Systematic Reviews, no. 3 (2010): CDoo5182. Adherence to modern guidelines for detection and treatment of hypertension has increased over the past decades, at least in North-western Europe; see Stephen Campbell et al., "Quality of Primary Care in England with the Introduction of Pay for Performance," New England Journal of Medicine 357, no. 2 (2007): 181-9o; Erkki Vartiainen et al., "Thirty-Five-Year Trends in Cardiovascular Risk Factors in Finland," International Journal of Epidemiology 39, no. 2 (2009): 504-18. As a result, the number of hypertensives whose blood pressure is under control has increased; see Benjamin A. Steinberg et al., "Nine-Year Trends in Achievement of Risk Factor Goals in the US and European Outpatients with Cardiovascular Disease," American 
Advances in the treatment of cerebrovascular disease are of even more recent date. Before World War II, supportive care of the acute phase, followed by rehabilitation of bodily functions that had become impaired, was the only option. However, from the 1950 on onwards survival after a stroke started to improve. This was probably due to more effective treatment of some of its lethal complications (e.g., pneumonia, which could now be treated with antibiotics), and as a side-effect of more rehabilitation (which reduced the risks of being confined to bed). ${ }^{19}$

It was only in the 1980s and 199os that causal treatment of the acute event of stroke itself became possible, in the form of thrombolytic therapy for ischaemic stroke, and surgical removal of blood clots for haemorrhagic stroke. Such advanced treatments required highly specialized personnel, and were most effective if delays between the event and the start of treatment were short. Rapid transportation of stroke patients to specialized 'stroke units' therefore became more and more the norm in the 1990s. ${ }^{20}$

What has been the impact of these advances in prevention and treatment on the incidence and mortality of cerebrovascular disease? As usual, only mortality trends can be followed for a longer period, and as shown in Figure 23 mortality from cerebrovascular disease has run a somewhat irregular course since the beginning of the 2oth century. This is partly due to the fact that the trends for haemorrhagic stroke and for ischaemic stroke - which cannot be distinguished in routine statistics - have been fundamentally different.

In countries where it has been possible to separate the two using clinical information, e.g., in England \& Wales, it has been found that mortality from haemorrhagic stroke has declined since the beginning of the 2oth century, whereas mortality from ischaemic stroke has followed a course similar to that of ischaemic heart disease: rising until the 1970s, and then declining. The trend of mortality from cerebrovascular disease in England \& Wales thus results from the superposition of two different trends: an epidemic-like pattern of

Heart Journal 156, no. 4 (2008): 719-27; Paola Primatesta and Neil R. Poulter, "Improvement in Hypertension Management in England," Journal of Hypertension 24, no. 6 (2006): 1187-192.

19 W. Michael Garraway, Jack P. Whisnant, and Ivo Drury, "The Changing Pattern of Survival Following Stroke," Stroke 14, no. 5 (1983): 699-703.

20 Systematic reviews have concluded that stroke patients who receive organised inpatient care in a stroke unit are more likely to be alive, independent, and living at home one year after the stroke; see Stroke Unit Trialists' Collaboration, "Organised Inpatient (Stroke Unit) Care for Stroke," Cochrane Database Systematic Reviews, no. 9 (2013): CDooo197. 
ischaemic stroke superimposed on the long-term decline of haemorrhagic stroke. $^{21}$

The tendency for haemorrhagic stroke to decline even before the introduction of antihypertensive treatment in the 1960 os is probably due to 'spontaneous' declines in the prevalence of hypertension. These will have occurred as a result of a reduction in the intake of salt, due to less use of salt for food conservation, and also perhaps as a result of an increase in the intake of fresh fruits and vegetables. Studies have shown that in the last decades of the 2oth century the prevalence of hypertension has continued to decline in many European countries, probably as a result of further dietary changes combined with better detection and treatment of hypertension. ${ }^{22}$

The 'rise-and-fall' of ischaemic stroke is partly due to the same risk factor trends as played a role in the 'rise-and-fall' of ischaemic heart disease. These include a rising and then declining prevalence of smoking, and a rising and then declining prevalence of high serum cholesterol. Reduced intake of salt, and better detection and treatment of hypertension have contributed to the decline of ischaemic stroke too. ${ }^{23}$

More recently, improvements in the treatment of stroke have contributed to declining mortality from both haemorrhagic and ischaemic stroke, as is clear from studies of trends in incidence and case fatality of stroke in recent decades, which found that both have declined. ${ }^{24}$

21 Debbie A. Lawlor et al., "Secular Trends in Mortality by Stroke Subtype in the 2oth Century," Lancet 36o, no. 9348 (2002): 1818-823.

22 That part of the decline in hypertension is due to reduced salt intake, part to improved detection and treatment of hypertension is the conclusion of several studies, including Primatesta and Poulter, "Improvement in Hypertension Management in England"; Emanuela Falaschetti et al., "Continued Improvement in Hypertension Management in England," Hypertension 53, no. 3 (2009): 480-86. Declines in stroke mortality have generally been larger in countries with stronger declines in systolic blood pressure; see Martin McKee and Johan P. Mackenbach, "Hypertension," in Successes and Failures of Health Policy in Europe, ed. Johan P. Mackenbach and Martin McKee (Maidenhead: Open University Press, 2013).

23 A study from England found that declines in stroke were due partly to reductions in smoking, cholesterol, and blood pressure, partly to increases in treatment with antiplatelet, lipid-lowering, and blood pressure lowering drugs; see Peter M. Rothwell et al., "Change in Stroke Incidence, Mortality, Case-Fatality, Severity, and Risk Factors in Oxfordshire," Lancet 363, no. 9425 (2004): 1925-933.

24 The contribution of incidence and case fatality to mortality decline has differed between countries. In Finland declining incidence was more important; see Juhani Sivenius et al., "Continuous 15-Year Decrease in Incidence and Mortality of Stroke in Finland," Stroke 35, no. 2 (2004): 420-25. In several other countries declining case fatality was more important; see, e.g., Isabelle Benatru et al., "Stable Stroke Incidence Rates but 


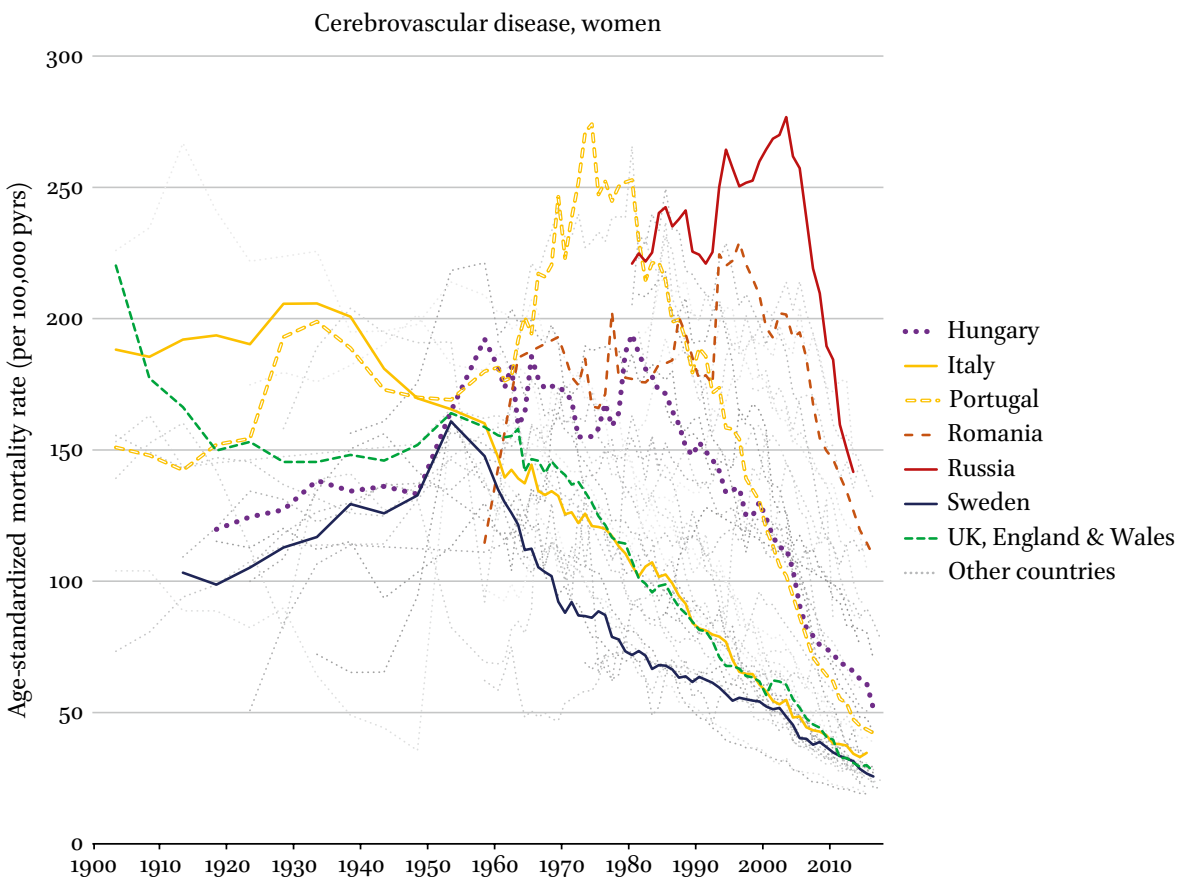

FIGURE 23 Trends in cerebrovascular disease mortality in Europe, 1900-2015

Notes: Quinquennial data before 1960

SOURCE OF DATA: SEE SUPPL. TABLE 1

Let us now return to Figure 23, which covers an unusually long time-range. Because data available in the repository of the World Health Organization do not go further back than 1950, trends in stroke mortality before the 1950s have only rarely been studied. ${ }^{25}$

Trends before World War II were highly variable. Stroke mortality declined in England \& Wales, probably reflecting the decline of haemorrhagic stroke mentioned above. However, it increased in many other countries, including Sweden, Italy, Portugal, and Hungary, all marked in the graph. In many countries, this rise continued in the post-war period and led up to a peak in the

Improved Case-Fatality in Dijon, France, from 1985 to 2004," Stroke 37, no. 7 (2006): 1674679; Janika Kôrv, Mai Roose, and Ain-Elmar Kaasik, "Changed Incidence and Case-Fatality Rates of First-Ever Stroke between 1970 and 1993 in Tartu, Estonia," Stroke 27, no. 2 (1996): 199-203; Halina Sienkiewicz-Jarosz et al., "Incidence and Case Fatality Rates of First-Ever Stroke," Neurologia i Neurochirurgia Polska 45, no. 3 (2011): 207-12.

25 For an overview of trends in stroke mortality, see Masoud Mirzaei et al., "Cerebrovascular Disease in 48 Countries: Secular Trends in Mortality 1950-2005," Journal Neurology Neurosurgery Psychiatry 83, no. 2 (2012): 138-45. 
1950 or 1960s, which we have earlier identified with the 'epidemic' of ischaemic stroke.

In most countries of Northern, Western and Southern Europe, stroke mortality has declined since the 1960s, with one important exception: Portugal. This country presents one of the most remarkable trends in Figure 23. Portugal already had a high level of stroke mortality before World War II, but experienced a true epidemic after the war, peaking at an exceptionally high level, only to be matched by countries of the former Soviet Union in the 1990s. The timing of this epidemic suggests that ischaemic stroke was the main culprit, but the underlying cause is likely to have been hypertension, because Portugal did not experience a similarly dramatic increase of ischaemic heart disease mortality (see Figure 22).

The Portuguese diet has long been very rich in salt, because foods that were salted for conservation have longer than elsewhere remained an important component of the Portuguese diet. This applies particularly to salted cod traditional Portuguese cookbooks reputedly contained more recipes for preparing salted cod than there are days in a calendar-year. The fact that a salty diet has lingered on for so much longer in Portugal, is likely due to the fact Portugal has long lagged behind other European countries in social and economic development. It has long remained isolated from international developments under the authoritarian government of António de Oliveira Salazar (governing from 1932 to 1968). Delays in introducing modern methods of hypertension management may also have played a role. ${ }^{26}$

Perhaps even more striking are the trends in Central-eastern and particularly Eastern Europe. In Czechoslovakia, Hungary, Bulgaria, Estonia, and Latvia, stroke mortality peaked in the 1980s, in Romania, Lithuania, and Ukraine in the 1990s, and in Russia and Moldova there was a double peak: a first one in the 1980 s and a second, even higher one in the first decade of the 21st century. These high levels and delayed declines of stroke mortality reflect high levels of

26 For a Portuguese study of the high frequency of stroke, see Manuel Correia et al., "Prospective Community-Based Study of Stroke in Northern Portugal," Stroke 35, no. 9 (2004): 2048-053. A somewhat speculative analysis of the political background to the delay in 'modernization' of the Portuguese diet can be found in Johan P. Mackenbach, "Bacalhao under the Ponte 25 De Abril: Impressions from Lisbon," European Journal Public Health 19, no. 1 (2009): 1 . A Portuguese study undertaken in 2003 found that only $11 \%$ of those with hypertension were controlled; see Mário Espiga Macedo et al., "Prevalence, Awareness, Treatment and Control of Hypertension in Portugal," Journal of Hypertension 23, no. 9 (2005): 1661-666. 
hypertension and delayed implementation of hypertension detection and control with modern antihypertensive drugs. ${ }^{27}$

The peaks in stroke mortality in Russia in 1994 and in 2003 resemble those seen for other causes of death (and for total mortality) and coincide with low points in the economy and peaks in excessive alcohol consumption, suggesting that stroke mortality was influenced by either or both of the two. Downturns in the economy may have increased excessive alcohol consumption, and/or may have decreased access to prevention and treatment for hypertension and stroke. ${ }^{28}$

\section{Diabetes Mellitus}

Diabetes mellitus is a disease that comes in two forms. Type 1 usually starts in childhood or adolescence, and is probably due to autoimmune destruction of the pancreatic cells that make insulin, a hormone that is needed for glucose metabolism. Type 2 occurs mainly in older adults, and is due to inability of the body to appropriately respond to insulin, which often happens in obesity. Currently, more than $90 \%$ of diabetics in Europe have type 2 diabetes.

Both types of diabetes can be fatal, but type 1 used to cause early death in an acute coma, whereas type 2 has a more protracted course and mainly causes death in middle- or old-age through cardiovascular or renal complications. Type 1 needs to be treated with insulin, which was discovered in 1922, whereas type 2 can often also be treated with oral hypoglycaemic drugs, which were developed in the 195 os. $^{29}$

Clinical case-series have shown a strong increase in the survival of diabetes patients, not only due to the treatment of diabetes itself, but also due to prevention and treatment of its complications, such as infection (by means of

27 V. Baláz et al., "Prevalence of Ischaemic Heart Disease Risk Factors in Warsaw and Bratislava. Part 2: Hypertension," Cor et Vasa 22, no. 3 (1980): 140-46; L. Mark, A. Katona, and L. Deli, "An Attempt to Evaluate the Risk Factors Related to Coronary Heart Disease in Hungary," Cor et Vasa 33, no. 4 (1991): 265-72. In the Soviet Union access to modern antihypertensive drugs such as thiazide diuretics, beta blockers and ACE inhibitors was limited, as was awareness among professionals of the benefits of regular treatment of asymptomatic individuals; see Bayard Roberts et al., "Irregular Treatment of Hypertension in the Former Soviet Union," Journal Epidemiology Community Health 66, no. 6 (2012): $482-88$.

28 As shown in Andreev et al., "Evolving Pattern" other causes of death amenable to medical intervention fluctuated in a similar way, suggesting that changes in access or quality of health care did play a role.

29 For the development of effective treatments for diabetes, see Chris Feudtner, Bittersweet (Chapel Hill \& London: University of North Carolina Press, 2004); Awad M. Ahmed, "History of Diabetes Mellitus," Saudi Medical Journal 23, no. 4 (2002): 373-78. 
antibiotics), cardiovascular disease (by means of cardiovascular risk management) and renal failure (by means of dialysis). Nevertheless, diabetes patients still have higher mortality than non-diabetics. ${ }^{30}$

Unfortunately, both type 1 and type 2 diabetes are on the rise. Not only has increased survival pushed up prevalence, but the incidence of both forms of diabetes has also risen strongly. Diabetes mellitus was already known in antiquity, but was probably rare until the 2oth century, when it began to be noted that it was increasingly common, particularly in prosperous and urban areas. ${ }^{31}$

The rising incidence of type 1 diabetes in Europe during recent decades has been extensively documented in epidemiologic studies, and is basically unexplained. The latter also applies to the wide variation in incidence rates between countries. Within Europe, there is a striking North-South gradient, with a more than ten-fold range of variation between Finland, which has record-high rates, and the former Yugoslavia, which has the lowest rates. Both the rising trends and the geographical variations suggest that some aspect of the modern ways of life is involved, but it has so far not been possible to pin-point what this is. ${ }^{32}$

The incidence and prevalence of type 2 diabetes are also rising, but here the explanation is straightforward (Figure 24). Overweight and obesity are the single most important risk factor for type 2 diabetes, and the rise of type 2 diabetes has followed the rise of overweight and obesity. Over the past decades,

30 A famous case-series from the Joslin Clinic in Boston (USA) shows continuous reductions in mortality of diabetes patients between 1897 and 1961, with some acceleration of mortality decline among younger patients in the 1920s; see Herbert H. Marks, "Longevity and Mortality of Diabetics," American Journal of Public Health and the Nations Health 55, no. 3 (1965): 416-23. In Denmark, survival of diabetes type 1 patients treated in a central hospital improved considerably between 1933 and 1972; see K. Borch-Johnsen, S. Kreiner, and T. Deckert, "Mortality of Type 1 (Insulin-Dependent) Diabetes Mellitus in Denmark," Diabetologia 29, no. 11 (1986): 767-72. Survival has continued to improve in the last decades of the 2oth century; see Charbel Abi Khalil et al., "Cause-Specific Mortality in Diabetes: Recent Changes in Trend Mortality," European Journal of Preventive Cardiology 19, no. 3 (2012): 374-81.

31 For a short history of diabetes before the 1950s, see Henschen, History, p. 195-99. Trends of type 1 diabetes during the 2oth century were reviewed in Edwin A.M. Gale, "The Rise of Childhood Type 1 Diabetes in the 2oth Century," Diabetes 51, no. 12 (2002): 3353-361.

32 For rising incidence and between-country variations in Europe, see Eurodiab ACE Study Group, "Variation and Trends in Incidence of Childhood Diabetes in Europe," Lancet 355, no. 9207 (2000): 873-76; J. Tuomilehto et al., "Record-High Incidence of Type I (InsulinDependent) Diabetes Mellitus in Finnish Children," Diabetologia 42, no. 6 (1999): 655-6o; Christopher C. Patterson et al., "Incidence Trends for Childhood Type 1 Diabetes in Europe During 1989-2003 and Predicted New Cases 2005-20," Lancet 373, no. 9680 (2009): 2027-033. 
Diabetes mellitus, both sexes

1200

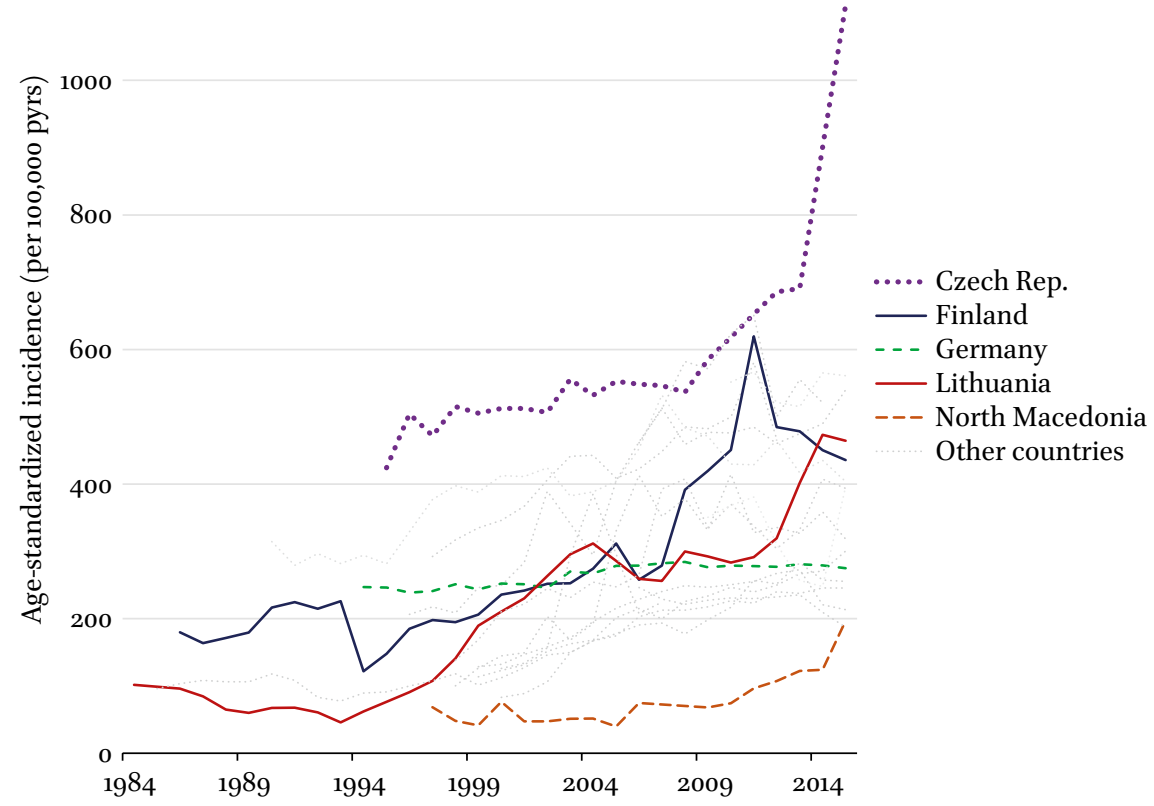

FIGURE 24 Trends in diabetes mellitus incidence in Europe, 1984-2015

Notes: Number of patients with newly diagnosed diabetes during the given calendar year as estimated from registrations of health care utilization SOURCE OF DATA: EUROPEAN HEALTH FOR ALL DATABASE (WWW.GATEWAY. EURO.WHO.INT, ACCESSED 04/10/19)

the prevalence of overweight and obesity have increased everywhere in Europe, although there are signs in some countries that the epidemic is levelling off among adolescents. ${ }^{33}$

Within Europe, both the prevalence of obesity and that of diabetes vary considerably between countries. Obesity is relatively less prevalent in the Nordic countries, the Netherlands, France, and the Baltic countries, and more prevalent in the South, Central-east and the United Kingdom. The latter

33 For a review of the epidemiology of type 2 diabetes, which is somewhat more complex than suggested here, see Lei Chen, Dianna J. Magliano, and Paul Z. Zimmet, "The Worldwide Epidemiology of Type 2 Diabetes Mellitus - Present and Future Perspectives," Nature Reviews Endocrinology 8, no. 4 (2012): 228-36. For recent trends in overweight and obesity, see Benjamin Rokholm, Jennifer L. Baker, and Thorkild I.A. Sørensen, "The Levelling Off of the Obesity Epidemic since the Year 1999," Obesity Reviews 11, no. 12 (2010): $835^{-46 .}$ 
country seems to act like a bridge to the United States, where the prevalence of obesity is even higher. The prevalence of diabetes follows roughly the same pattern. ${ }^{34}$

Long-term trends in diabetes mortality are somewhat chaotic (see Suppl. Figure 15). Certification and coding of diabetes as a cause of death have undergone many changes over time, and also differ between countries, so we should exercise caution in interpreting these trends. Nevertheless, some interesting patterns can be discerned. For example, despite the introduction of insulin in the early 1920s, a reduction in mortality from diabetes during the 1920 is not always apparent, which suggests that the effect was more limited at the population-level than suggested by clinical reports.

On the other hand, in many European countries diabetes mortality did decline strongly in the 1940s, reflecting the often noted decrease in the incidence of diabetes during the war, as a result of more restrictive food supplies. This decline also occurred in Spain, which went through a period of food scarcity after its Civil War (1936-1939). ${ }^{35}$

However, in the early 1950s diabetes mortality started to rise again, and reached a peak in many Northern and Western European countries in the $1970 \mathrm{~s}$ or 1980 . These will mainly have been deaths from the long-term cardiovascular complications of diabetes, as suggested by the fact that this peak in diabetes mortality coincided with the peak in ischaemic heart disease mortality. The subsequent decline in diabetes mortality is probably due to advances in the prevention and treatment of cardiovascular disease among diabetes patients.

\section{Stomach, Colorectal, Breast, Prostate Cancer}

During the 2oth century, cancer has become a much more important cause of death, not only as a percentage of all deaths, but also in absolute terms. This increase in cancer death rates was partly the result of increasing life expectancy, due to which people survived to older ages at which cancer is more frequent. Yet, this is not the whole story: we also see a strong increase when the

34 For between-country differences in the prevalence of obesity, based on nationally representative surveys with measurements of height and weight, see Anne Berghöfer et al., "Obesity Prevalence from a European Perspective: A Systematic Review," BMc Public Health 8, no. 1 (2008): 200. For differences in the prevalence of diabetes, see NCD Risk Factor Collaboration, "Worldwide Trends in Diabetes since 1980," Lancet 387, no. 10027 (2016): 1513-530.

35 See Gale, "The Rise of Childhood Type 1 Diabetes." For declining incidence of diabetes during World War II in the Netherlands, see J. Hermanides et al., "Lagere Incidentie van Diabetes Mellitus Type 2 bij Verandering van Leefstijl," Nederlands Tijdschrift voor Geneeskunde 152, no. 44 (2008): 2415-417. 

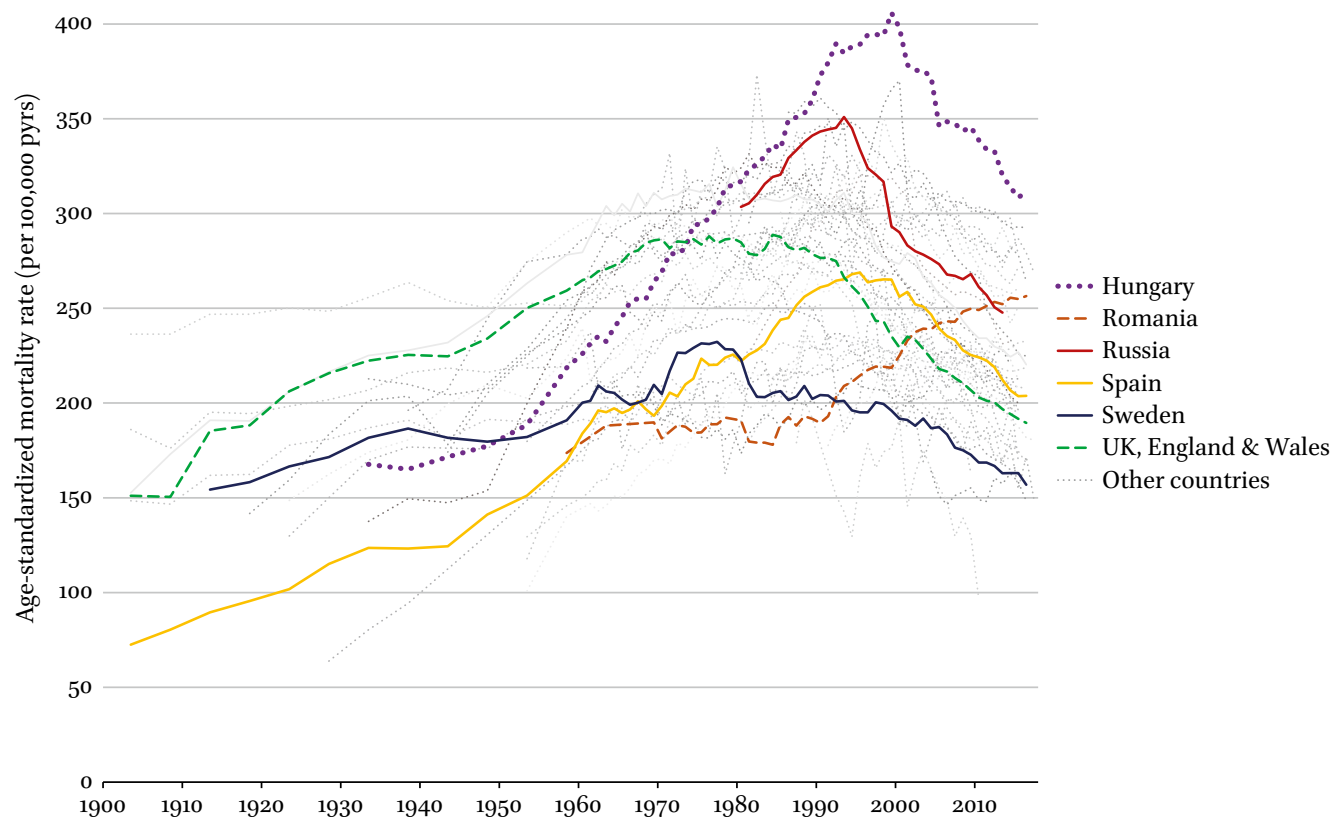

FIGURE 25 Trends in cancer mortality in Europe, 1900-2015

Notes: Quinquennial data before 1960

SOURCE OF DATA: SEE SUPPL. TABLE 1

effect of aging is removed, as in Figure 25. The age-standardized mortality rates from all cancers combined have risen dramatically in most European countries. They peaked somewhere between the 1970s and early 2000s, and then started to decline again, with large variations between countries.

Cancer registries with which trends in the occurrence of new cases of cancer can be followed, were created much later than cause-of-death statistics. Nevertheless, as we have seen in Chapter 2, cancer registries show rising incidence rates of cancer since whenever cancer registrations were established. This suggests that behind the rise of cancer mortality was a general rise of cancer incidence - although increased recognition likely also played a role, particularly of cancers located deeper within the body. ${ }^{36}$

36 There has been a long debate about whether the increase in cancer incidence and cancer mortality was real, or an artefact of better recognition, due to greater access to care and better diagnostic methods. The conclusion that a substantial part of the increase was real, 
When the rising frequency of cancer was first noted by contemporaries, at the end of the 19th century, cancer was certainly not a new disease. Millenniaold medical treatises had already described cancer. Still, cancer must long have remained less common, and the increasing frequency of cancer gave rise to many speculations about its causes. Cancer clearly seemed to be a 'disease of civilization': the price one paid for the on-going changes in society, which brought both good and bad things. The suspected causes of cancer ranged from environmental pollution to repressed emotions, and from degenerate morals to the increased survival of people with a hereditary predisposition to cancer. $^{37}$

Currently, cancer is understood as a 'genetic' disease, in the sense that its 'pathologic onset' is a change in cellular DNA that leads to uncontrolled cell growth. More specifically, cancer is believed to arise from mutations in the DNA of tissue-specific stem cells. These are undifferentiated cells that are present in small numbers in all organs, and that constantly multiply to produce the new differentiated cells necessary for tissue maintenance and repair. Cancerproducing mutations may occur as a result of exposure to 'mutagenic' factors such as radiation, carcinogenic substances and - perhaps surprisingly - sex hormones, or as a result of random errors during the replication of these cells' DNA when they divide. ${ }^{38}$

is based on several arguments. Increases were not only seen for cancers in which diagnostic techniques had improved but also for cancers in which they had not. Also, for many common cancers, increases in incidence or mortality can be explained from increasing exposure to well-known causes such as tobacco smoking. For an overview of these discussions, see Robert N. Proctor, Cancer Wars (New York: Basic Books, 1995), Chapter 1.

37 For a general history of cancer, of how it was understood, and of how prevention and treatment developed over time, see Siddhartha Mukherjee, The Emperor of All Maladies (New York etc.: Scribner, 2010). A more politically oriented history of cancer can be found in Proctor, Cancer Wars. The putative link between cancer and psychological or cultural factors made cancer a metaphor for personal failings, and a source of guilt and shame, as famously described in Susan Sontag, Illness as Metaphor (New York: Farrar, Straus \& Giroux, 1978).

38 Two types of mutations are thought to be required for normal cells to become cancer cells: mutations that activate an 'oncogene' (i.e., a gene that promotes cell proliferation) and mutations that de-activate 'tumour-suppressor genes' (genes that limit cell proliferation). There is controversy about the relative importance of exposure to mutagenic factors versus that of random replication errors, with some oncologists arguing that random replication errors account for the large majority of cancers; see Cristian Tomasetti and Bert Vogelstein, "Variation in Cancer Risk among Tissues Can Be Explained by the Number of Stem Cell Divisions," Science 347, no. 6217 (2015): 78-81; Cristian Tomasetti, Lu Li, and Bert Vogelstein, "Stem Cell Divisions, Somatic Mutations, Cancer Etiology, and Cancer Prevention," Science 355, no. 6331 (2017): 1330-334. However, others argue that random replication errors contribute only $10-30 \%$ of lifetime cancer risk; see Song Wu et al., 
Any increase in the occurrence of cancer must therefore be the result of an increase in the exposure to mutagenic factors, and as we will see below trends in many common cancers can indeed be understood in this way. However, the fact that the risks of cancer in so many different organs, and linked to so many different exposures, went up during the 2oth century raises a further and deeper question. Is there a common factor underlying all these changes? Why has there been a general rise of cancer - and not of many other diseases that afflict the human body - during this stage of human development? If a vague reference to 'civilization' does no longer satisfy us, what else could it be?

One possibility is that the rise of cancer is due to a generalized increase in exposure to a much wider range of chemical substances than our ancestors were exposed to. Our industries have increased the production of almost everything, in almost infinite chemical variation, bringing prosperity but also exposing workers and consumers to more carcinogens. Environmental pollution increased the inhalation and ingestion of carcinogenic substances by everyone in the population. However, other sources of carcinogens were probably more important. Increased agricultural production has allowed us to eat more and to live on a less monotonous diet, exposing us to a larger variety and to larger quantities of natural carcinogens. The rise of cigarette smoking and excessive alcohol consumption can also be seen as obvious - and quantitatively very important - examples of this generalized increase in exposure to a wider range of chemical substances. ${ }^{39}$

Yet, the rise of these 'unfavourable exchanges with the environment' is unlikely to be the whole explanation. Think of breast cancer, which as we will see below has risen as a result of changes in reproductive behaviour, which have increased exposure of breast tissue to oestrogen. Although this change was mainly driven by changes in fertility behaviour, which could be regarded as changes in how women interacted with their environment, it has little to do with increased exposure to chemical substances. It is inevitable to also invoke 'design failures' when we want to explain the generalized rise of cancer during

"Substantial Contribution of Extrinsic Risk Factors to Cancer Development," Nature 529, no. 7584 (2016): 43-7. In view of the large variations in cancer risk between populations and over time, the latter position seems much more credible.

39 This question has been discussed extensively, not only in the late 19th and early 2oth centuries, but also more recently. During the 1960 os and 1970s, there were wide-spread suspicions that the rise of cancer was due to an increase of industrially produced chemical pollutants (see Proctor, Cancer Wars, Chapter 3 ). These ideas were refuted by Doll and Peto's 1981 report, mentioned above, which showed that most cancers were due to behaviourally mediated factors (diet, tobacco, alcohol, sexual behaviour, ...) (Doll and Peto, "Causes"). 
the 2oth century. Humans appear to be highly vulnerable to a disturbance of the biological system that regulates cell proliferation. Many different exposures, to both external and internal agents, can cause a break-down of this system, suggesting that it is just not robust enough. To be more precise: evolution has apparently not selected us for fitness in an environment in which this system comes under attack so frequently. ${ }^{40}$

After this general introduction, let's now look at the secular trends for a few specific cancers, focusing on some of the most important ones. The trend for all cancers combined that we saw in Figure 25, actually hides some striking differences between cancers originating in different organs.

Stomach cancer is one the few cancers for which mortality already declined in North-western Europe before World War II (see Suppl. Figure 16). It is not really possible to identify the starting-point of this decline, although in some of these countries, such as Norway, stomach cancer mortality appears to have peaked around 1920. For Southern European countries, the trends can be followed since the 1930s or 1940s, and show a peak in the 1950s for Italy, the 1960s for Spain and Greece, and the 1970s for Portugal. In other European regions, stomach cancer mortality declined from the moment trend data are available, but suggest a considerable delay as compared to North-western Europe, particularly in Eastern Europe. All-in-all, it seems likely that the long-term trend for stomach cancer has followed a 'rise-and-fall' pattern, with a peak somewhere between the last decades of the 19th century and the 1970s. ${ }^{41}$

The decline of stomach cancer has been called 'an unplanned triumph', and it is certainly true that the decline cannot be attributed to any planned interventions. Current insights into the aetiology of stomach cancer suggest that the secular decline is due to a combination of two factors. The first factor is a

$40 \quad$ This 'design failure' was already briefly mentioned in Chapter 3, when we discussed the difficulty of our organism to deal effectively with 'entropy' (random errors in DNA replication). Our organism is also imperfect in dealing with non-random errors in DNA, such as those due to mutagenic factors. Most of these errors are removed in time, but a tiny fraction escapes and causes cancer. This 'design imperfection' has not disappeared during our evolution, probably because a higher degree of perfection was not necessary for our genetic material to be propagated from one generation to the next: most cancers kill after we have reproduced (Kirkwood, Time).

41 There are many studies documenting the secular decline of stomach cancer mortality, e.g., Levi et al., "Cancer Mortality in Europe." For a recent update, see Karim-Kos et al., "Recent Trends." For an up-to-date overview of the epidemiology of stomach cancer, see Catherine De Martel and Julie Parsonnet, "Stomach Cancer," in Cancer Epidemiology and Prevention (Fourth Edition), ed. Michael Thun et al. (Oxford etc.: Oxford University Press, 2017). I have not found literature on a possible rise of stomach cancer before the 2oth century. 
declining prevalence of Helicobacter pylori infection. Infection with this micro-organism is not only involved in the aetiology of peptic ulcer (see Chapter 5), but also in that of a large majority of cases of stomach cancer. It is not exactly known how this infection causes cancer. One of the possible pathways is that, as in other chronic infections leading to cancer, the bacteria form nitrosamines from other nitrous compounds present in food. Nitrosamines are potent carcinogenic substances which are present in some foods, but can also be produced within the body. Over the 2oth century, the prevalence of Helicobacter pylori infection has gradually declined, as a result of increased hygiene and smaller families. ${ }^{42}$

The second factor contributing to the decline of stomach cancer is changes in diet. Epidemiologic studies have shown that consumption of salted and pickled foods increases the risk of stomach cancer, whereas consumption of fruits decreases this risk. This is probably because salted and pickled foods contain nitrosamines, whereas fruits contain anti-oxidants which are thought to protect against DNA damage. Over the 2oth century, the consumption of the first has declined considerably, whereas consumption of the second has increased. Both changes were made possible by the introduction of refrigeration, which reduced the use of salt for food preservation and facilitated year-round transport and storage of fresh produce. Along the same lines, a historical increase in the intake of salted and pickled foods may then explain the rise of stomach cancer in previous time-periods. ${ }^{43}$

42 The decline of stomach cancer thus shares some of its causes with the decline of peptic ulcer (through reduced infection with Helicobacter pylori). The expression "unplanned triumph" was used in Christopher P. Howson, Tomohiko Hiyama, and Ernst L. Wynder, "The Decline in Gastric Cancer: Epidemiology of an Unplanned Triumph," Epidemiologic Reviews 8, no. 1 (1986): 1-27. For the role of a declining prevalence of Helicobacter pylori infection, see, e.g., M. Blanca Piazuelo, Meira Epplein, and Pelayo Correa, "Gastric Cancer: An Infectious Disease," Infectious Disease Clinics 24, no. 4 (2010): 853-69. On the role of nitrosamines, see Paula Jakszyn and Carlos Alberto González, "Nitrosamine and Related Food Intake and Gastric and Oesophageal Cancer Risk," World Journal of Gastroenterology 12, no. 27 (2006): 4296-303.

43 An interesting study looking at the role of the refrigerator in reducing the risk of stomach cancer (in South Korea, which has modernized more recently than most European countries) is Boyoung Park et al., "Ecological Study for Refrigerator Use, Salt, Vegetable, and Fruit Intakes, and Gastric Cancer," Cancer Causes \& Control 22, no. 11 (2011): 1497-503. Helicobacter pylori has accompanied humans on their journey out of Africa, and is found in all human populations around the world. However, the European variants of the microorganism have mutations that make it particularly virulent; see Nuri Kodaman et al., "Human and Helicobacter Pylori Coevolution Shapes the Risk of Gastric Disease," Proceedings of the National Academy of Sciences 111, no. 4 (2014): 1455-460. 
In contrast to stomach cancer, most other cancers have had rising incidence trends from the first moment of cancer registration in the 1950s or 196os. These range from cancer of the oesophagus to non-Hodgkin's lymphoma and from laryngeal cancer to malignant melanoma of the skin. For some of these cancers recent trends have reversed, showing that the familiar 'rise-and-fall' pattern also manifests itself for these diseases. It is probably fair to say that - in contrast to the decline of stomach cancer - these favourable trends are mostly a result of deliberate efforts to reduce the risk of cancer and/or to reduce its case fatality.

Over the past half century, the incidence of colorectal cancer has increased in many European countries, probably as a consequence of a rise of several of its main risk factors, including a diet low in fibre and rich in red and/or processed meat, and a sedentary lifestyle and obesity. Current understanding of colorectal cancer suggests that these risk factors work as follows, illustrating how complex 'unfavourable exchanges with the environment' can be. Like salted and pickled foods, processed meat is an exogenous source of nitrosamines, but the other factors involved in the rise of colorectal cancer promote exposure to endogenously produced carcinogens. Intestinal bacteria, essential for digestion, produce carcinogens from compounds naturally present in food. Both fibre and physical activity increase bowel motility, thereby reducing transit time and shortening the duration of exposure to carcinogenic faecal contents. Finally, obesity leads to increased secretion of insulin, which promotes cell proliferation. ${ }^{44}$

Whereas colorectal cancer incidence has recently stabilized (at a high level) in some countries in North-western Europe, it is still rising in other parts of Europe. Mortality from colorectal cancer, however, is declining in many countries after reaching a peak somewhere between the 1970s and early 2000 s (see Suppl. Figure 17). The decline is mainly due to increased survival as a result of more effective treatment, plus (in some North-western European countries) a favourable effect on disease incidence from mass screening for pre-cancerous polyps. ${ }^{45}$

Mortality from breast cancer has also started to decline in many countries, after decades of continuous increase which probably started in the late 19th century (Figure 26). Like in the case of colorectal cancer, the rising mortality

44 For the current understanding of colorectal cancer, see Kana Wu et al., "Cancers of the Colon and Rectum," in Cancer Epidemiology and Prevention (Fourth Edition), ed. Michael Thun et al. (Oxford etc.: Oxford University Press, 2017).

45 Karim-Kos et al., "Recent Trends"; Wu et al., "Cancers of the Colon and Rectum"; Carlo La Vecchia et al., "Cancer Mortality in Europe, 2000-2004, and an Overview of Trends since 1975," Annals of Oncology 21, no. 6 (2009): 1323-360. 


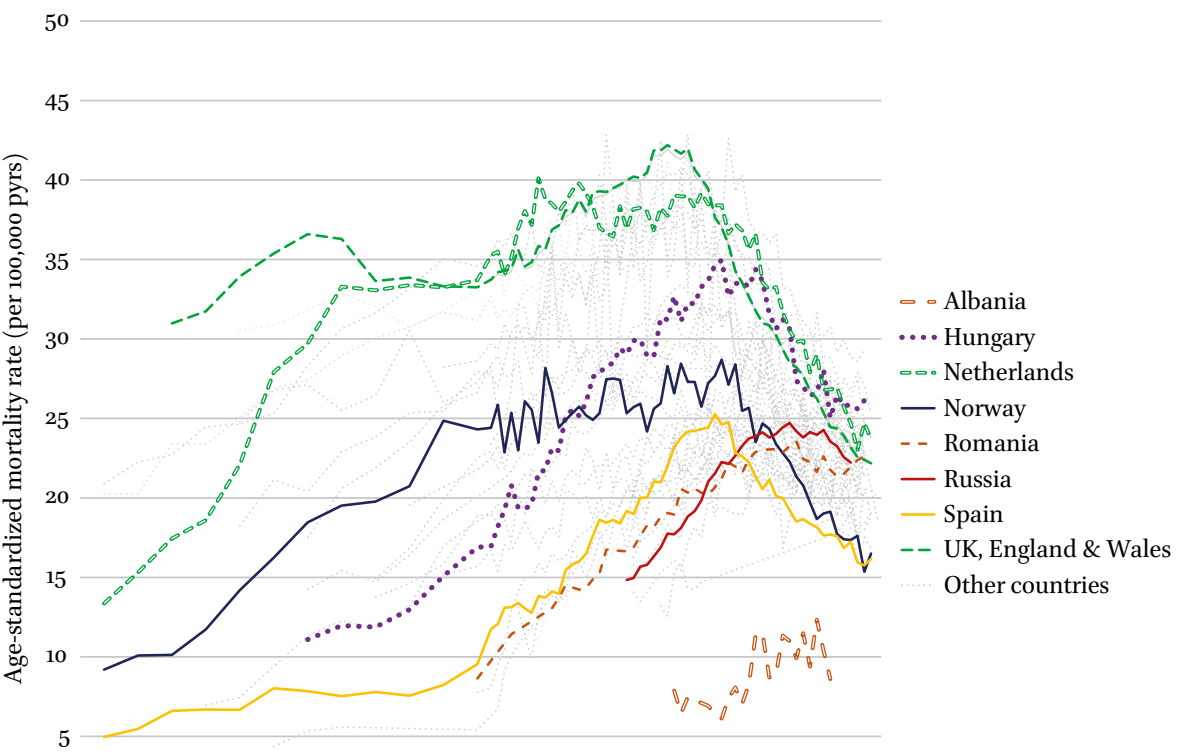

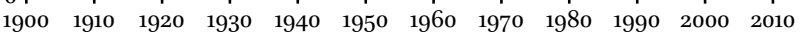

FIGURE 26 Trends in breast cancer mortality in Europe, 1900-2015

Notes: Quinquennial data before 1960

SOURCE OF DATA: SEE SUPPL. TABLE 1

from breast cancer during most of the 2oth century was due to a rising incidence, which in its turn was due to a rising prevalence of several of breast cancer's main risk factors. These include reproductive factors (young age at menarche, no or few children, older age at first birth, low breast-feeding, older age at menopause) as well as some other factors (e.g., obesity, alcohol use and hormone replacement therapy). Here again, we have a disease that is a direct consequence of the modern way of life, but in a way that defies easy attribution to 'unfavourable exchanges with the environment'.

Current understanding of breast cancer aetiology suggests that the crucial factor is exposure of breast tissue to oestrogen. This sex hormone, whose production rises and falls during each menstrual cycle, promotes cell growth in the breast and other reproductive organs, which is important for reproduction but also increases the risk of uncontrolled cell proliferation. The reproductive factors mentioned above are all determinants of the number of menstrual cycles women have during their life-time. For example, women bearing no or few children have more menstrual cycles than women with more children, because 
menstrual cycles stop during pregnancy. Also, fat tissue produces oestrogen, which probably explains the association between obesity and breast cancer. ${ }^{46}$

Fortunately, mortality has started to decline as a result of improvements in treatment (resulting in increased survival) and introduction of mass screening for early stages of breast cancer (resulting in - paradoxically - a further increase in incidence). ${ }^{47}$

Mortality from prostate cancer also shows a striking 'rise-and-fall' pattern, with rises starting before World War II (see Suppl. Figure 18). Although prostate cancer is very frequent, its aetiology is not well understood. Many environmental and lifestyle factors have been investigated, but none shows a consistent relationship with the risk of prostate cancer. Like other cancers, prostate cancer has genetic determinants, but these cannot explain its rapid rise in incidence and mortality over most of the 2oth century. Improved detection most likely plays a role, aided (in the last decades) by the introduction of a blood test for Prostate Specific Antigen (PSA). Nevertheless, mortality has recently started to decline in many European countries, probably as a result of earlier detection and improved treatment. ${ }^{48}$

For many more cancers, trends in mortality have partly become uncoupled from trends in incidence. This was due to sometimes substantial, but more often modest, improvements in survival. These improvements in survival have been won in a hard-fought and expensive battle which has explicitly been called a 'war on cancer', announced by US President Richard Nixon in 1971. Political mobilization over the threat of cancer led to huge investments in research over the following decades, both in the US and Europe. This has led to great strides in the understanding of cancer, and to advances in treatment which - from a public health perspective - have been rather underwhelming. ${ }^{49}$

$46 \quad$ For the current understanding of breast cancer, see Louise A. Brinton, Mia M. Gaudet, and Gretchen L. Gierach, "Breast Cancer," in Cancer Epidemiology and Prevention (Fourth Edition), ed. Michael Thun et al. (Oxford etc.: Oxford University Press, 2017).

47 La Vecchia et al., "Cancer Mortality"; Brinton et al., "Breast Cancer"; Karim-Kos et al., "Recent Trends."

48 Karim-Kos et al., "Recent Trends"; La Vecchia et al., "Cancer Mortality”; Catherine M. Tangen, Marian L. Neuhouser, and Janet L. Stanford, "Prostate Cancer," in Cancer Epidemiology and Prevention (Fourth Edition), ed. Michael Thun et al. (Oxford etc.: Oxford University Press, 2017).

49 See Proctor, Cancer Wars for the history of the war against cancer. Too slow increases in cancer survival rates fuelled criticisms of the 'war on cancer'; see John C. Bailar III and Elaine M. Smith, "Progress against Cancer?," New England Journal of Medicine 314, no. 19 (1986): 1226-232; John C. Bailar and Heather L. Gornik, "Cancer Undefeated," New England Journal of Medicine 336, no. 22 (1997): 1569-574. 


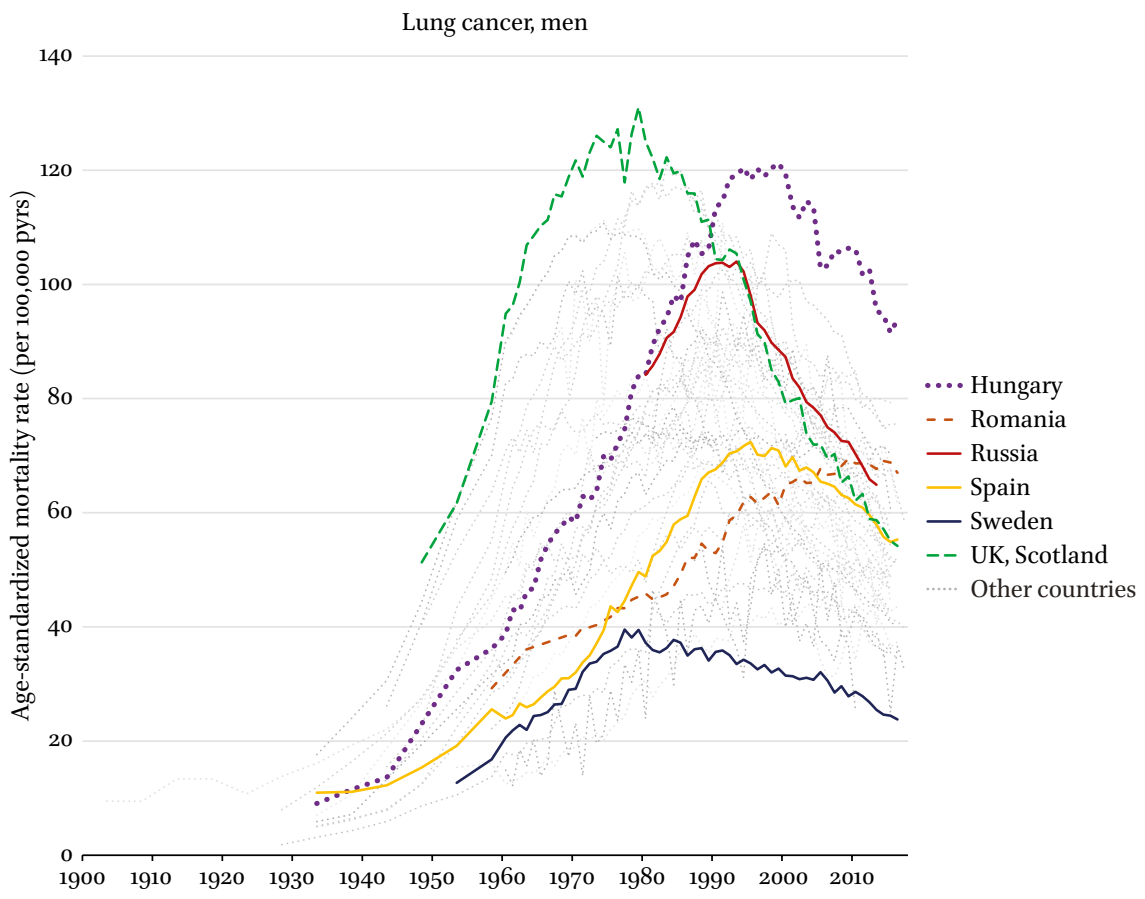

FIGURE 27 Trends in lung cancer mortality in Europe, 1900-2015

Notes: Quinquennial data before 1960

SOURCE OF DATA: SEE SUPPL. TABLE 1

\section{Lung Cancer}

Trends in lung cancer will be discussed in more detail, because these are almost completely determined by trends in smoking behaviour, which also determine trends in many other health outcomes. As survival from lung cancer used to be very poor, trends in incidence and mortality are very similar, and as trends in lung cancer mortality are available for more countries over a longer period of time, these are illustrated in Figure 27. Exceptionally, trends for men and women are very different (see Suppl. Figure 19).

Among men, we see a very striking pattern of 'rise and-fall' in nearly all European countries, but with enormous differences between countries in timing and height of the peak. Lung cancer mortality rates peaked in the mid- to late1970 in the United Kingdom, and in the early 199os in countries like Spain and Hungary. Whereas Sweden's lung cancer mortality peaked at around 40 deaths per 100,000, Scotland's peaked at 130 deaths per 100,000.

Among women, the general pattern is that of a dramatic increase in lung cancer mortality rates. Only few countries have already reached their peak in 
the early 2000s, e.g., United Kingdom, Denmark, Sweden. Here again, levels of lung cancer mortality differ enormously between countries, with Sweden peaking at a much lower level than Denmark or the United Kingdom. And whereas lung cancer mortality rates among Eastern European men are comparatively high, rates among Eastern European women are still comparatively low. 50

Cigarette smoking is the main risk factor for lung cancer mortality, accounting for between 80 and $90 \%$ of all cases. Cigarette smoke contains a bewildering array of carcinogens, including nitrosamines but also many others. Trends in lung cancer thus mainly reflect population histories of smoking, with a delay of 20-30 years. Survey data on self-reported smoking and tobacco sales data indeed show similar patterns of 'rise-and-fall'. Smoking among men peaked in the 1950s in many Northern and Western European countries, and later elsewhere, whereas smoking among women is still on the rise in many countries in Southern and Eastern Europe. Tobacco sales peaked in the 1970s in Northern and Western Europe, and in the 1980s, 199os or even later in Southern and Eastern Europe. ${ }^{51}$

This pattern of 'rise-and-fall' - of both smoking and lung cancer - has understandably been characterized as an 'epidemic'. The 'cigarette epidemic' follows a characteristic pattern that has been compared to the diffusion of innovations. It starts among 'early adopters', who tend to be men and people in higher social classes, and then becomes mainstream, being gradually adopted by women and people in lower social classes as well. When the health risks become widely known and smoking loses its power of social distinction, it is renounced first by the same people who were 'early adopters', i.e., men and higher social classes. This produces a similar pattern of socially differentiated 'rise-and-fall' for lung cancer mortality, but with a few decades delay. ${ }^{52}$

5o Detailed analyses of recent trends in lung cancer in European countries can be found in, e.g., P. Brennan and Issy Bray, "Recent Trends and Future Directions for Lung Cancer Mortality in Europe," British Journal of Cancer 87, no. 1 (2002): 43-8; J. Ferlay et al., "Cancer Incidence and Mortality Patterns in Europe," European Journal of Cancer 103 (2018): 35687; Karim-Kos et al., "Recent Trends."

51 Trends in smoking behaviour in Europe can be followed in the wHo Health for All Database (https://gateway.euro.who.int/en/datasets/european-health-for-all-database/). Trends in tobacco sales can be found in Barbara Forey et al., International Smoking Statistics (Oxford etc.: Oxford University Press, 2009).

$5^{2}$ The concept of the 'tobacco epidemic' was introduced by Alan D. Lopez, Neil E. Collishaw, and Tapani Piha, "A Descriptive Model of the Cigarette Epidemic in Developed Countries," Tobacco Control 3, no. 3 (1994): 242-47. It was later somewhat refined in Michael J. Thun et al., "Stages of the Cigarette Epidemic on Entering Its Second Century," Tobacco Control 21, no. 2 (2012): 96-101. While this concept helps to recognize regularities in trends 
Indirectly, trends in lung cancer tell us much about the role of smoking in determining trends and variations in over-all population health. In countries where peak lung cancer mortality rates among men have been very high, such as the United Kingdom, the Netherlands and Hungary, total smoking-attributable mortality has also been very high, accounting for more than $30 \%$ of male allcause mortality in peak-years. In most other countries, smoking-attributable mortality peaked between 20 and $30 \%$ of all-cause mortality, which of course is still very high. The main exception is Sweden where it was never more than $12 \% .^{53}$

The 'cigarette epidemic' has a long history. Tobacco was brought from the Americas to Europe in the 16th century, and was at first mostly used as snuff and in pipes. It was only after the invention of 'cigarettes' in the 1840 s and a machine for the industrial production of cigarettes in the 1880s, that cigarette smoking became a mass habit in some countries in the early decades of the 2oth century. As smoking is still prevalent and smoking-attributable mortality is still high, even in countries where the 'cigarette epidemic' started, this is clearly a very slow epidemic that takes more than a century to play out.

There are at least three reasons for this. First, nicotine is a strongly addictive substance, and after young people have taken up smoking, many of them continue smoking during their lives. This also explains why smoking and lung cancer trends manifest themselves as birth-cohort phenomena. Because replacement of generations takes time, the epidemic takes many decades to unfold. Second, there is a long delay between exposure to tobacco smoke and some of its major health effects, particularly lung cancer, other cancers, and COPD, putting decades between the peak in smoking and the peak in lung cancer. Third, the policy response to smoking and its health effects has been slow. Sadly, decades have passed between the demonstration of the harmful effects of smoking and the implementation of systematic tobacco control measures. This was partly due to active resistance by the tobacco industry, partly due to reluctance

of smoking and lung cancer, one should not be misled to think that the decline of smoking automatically follows its rise, like the decline of infectious diseases follows their rise when the number of susceptibles becomes too low to sustain agent's spread.

At least two methods have been developed to derive the quantitative contribution of smoking to total mortality from the level of lung cancer mortality: Richard Peto et al., "Mortality from Tobacco in Developed Countries: Indirect Estimation from National Vital Statistics," Lancet 339, no. 8804 (1992): 1268-278; Samuel H. Preston, Dana A. Glei, and John R. Wilmoth, "A New Method for Estimating Smoking-Attributable Mortality in HighIncome Countries," International Journal of Epidemiology 39, no. 2 (2009): 430-38. The estimates presented here come from Thun et al., "Stages." One explanation for the exceptionally low rates of smoking, and low proportions of smoking-attributable deaths, in Sweden is the wide-spread use of 'snus' (see Chapter 7). 
on the part of public authorities to interfere with behaviour that was perceived to be an individual choice. ${ }^{54}$

In order to more fully understand the 'cigarette epidemic', we must distinguish between 'supply' and 'demand'. Like in the case of other consumption products, the rise in cigarette use was both a matter of supply responding to demand, and demand responding to supply. The tobacco industry has been highly effective in promoting cigarette use, e.g., by clever advertising campaigns, by raising nicotine content and adding compounds that help to tolerate tobacco smoke in the lungs, and by developing "light cigarettes" when ordinary cigarettes were shown to have harmful effects on health. The tobacco industry has also often tried to delay government action against smoking, by hiding internal information on the harmful effects of smoking, by spreading misinformation, and by lobbying Ministers and parliaments.

While this is all true and highly objectionable, we should not close our eyes to the fact that there is also a demand-side. Nicotine has psychogenic effects which are appreciated by tobacco users. When it reaches the brain it acts as a stimulant, improves mood and concentration, and gives a feeling of relaxation and decreased stress. These are all temporary effects, and withdrawal of nicotine increases anxiety, thereby creating dependence. Yet, these psychogenic effects must have had an important function in European societies for smoking to become so wide-spread. One plausible explanation is that smoking helped to relieve stress and frustration in times of rapid economic and social change - and, in contrast with other forms of mood regulation, such as alcohol consumption, could be combined with a high pace of work.

Cigarette smoking was also a cultural phenomenon: it came to symbolize all kinds of positive things - often cleverly reinforced by the marketing strategies of the tobacco industry - which increased its appeal among potential consumers. Cigarette smoking came to be perceived as a sign of 'masculinity', perhaps because smoking became popular among soldiers, first in the Crimean war and

54 Histories of smoking, the discovery of its harmful effects, and the development of antismoking policies can be found in, e.g., Richard Doll, "Tobacco: A Medical History," Journal of Urban Health 76, no. 3 (1999): 289-313; Arthur W. Musk and Nicholas H. De Klerk, "History of Tobacco and Health," Respirology 8, no. 3 (2003): 286-90; Robert N. Proctor, "The History of the Discovery of the Cigarette-Lung Cancer Link," Tobacco Control 21, no. 2 (2012): 87-91. Extensive histories, focusing on the pernicious role of the tobacco industry, particularly in the US, can be found in Robert N. Proctor, Golden Holocaust (Berkeley etc.: Univ of California Press, 2011); Allan M. Brandt, The Cigarette Century (New York: Basic Books, 2007). A specifically British, and somewhat more benign, history is Virginia Berridge, Marketing Health: Smoking and the Discourse of Public Health in Britain, 1945-200o (Oxford etc.: Oxford University Press, 2007). 
later in World Wars I and II, during which cigarettes were distributed among soldiers in their rations. Originally, cigarette smoking was seen as unsuitable for women, because it signalled promiscuity, but when smoking among women became more acceptable, it came to symbolize 'emancipation', which strongly increased its appeal among women. More generally, cigarette smoking signalled 'modernity', which propelled it through European populations in parallel with socioeconomic modernization. ${ }^{55}$

Fortunately, in view of its disastrous health effects, the rise in smoking was followed by a fall, at least among men, and hopefully soon also among women. This decline started when the harmful effects of smoking became more widely known, and this again was a long process. Rising rates of lung cancer were already noticed by pathologists and surgeons around the turn of the 2oth century. Suspicions that this rise was due to the increasing popularity of cigarette smoking were quite common in the medical profession in the 1930s, but still competed with alternative hypotheses.

The first epidemiological evidence for a connection between smoking and lung cancer came from case-control studies, the first of which was published in 1939 by a medical doctor working in Nazi Germany, later followed by a series of American and British case-control studies published in 1950. A few years later, the results were confirmed in a series of prospective cohort studies, again in the United States and the United Kingdom. Animal experiments, cellular pathology studies, and chemical studies of the compounds present in tobacco smoke completed the picture, and by the mid-1950s there was no longer room for reasonable doubt about the link between smoking and lung cancer. ${ }^{56}$

55 See, for example, Matthew Hilton, Smoking in British Popular Culture 1800-200o (Manchester: Manchester University Press, 200o); Virginia Berridge, Demons: Our Changing Attitudes to Alcohol, Tobacco, and Drugs (Oxford etc.: Oxford University Press, 2013). The shifting social significance of cigarette smoking can be followed in popular and highbrow culture through the ages; see Sander L. Gilman and Xun Zhou, Smoke: A Global History of Smoking (London: Reaktion Books, 2004).

56 The Nazis were preoccupied with smoking, long before the Allies were. The leaders of the Third Reich had very strict non-smoking policies including bans on smoking and extensive health education campaigns. In some of these the non-smoking Führer was used as an example for the German people, and anti-tobacco activists pointed out that while Churchill, Stalin and Roosevelt were all smokers, the three fascist leaders in Europe, Hitler, Mussolini and Franco, were non-smokers. The Nazis considered tobacco smoke a 'genetic poison', which would lead to a degeneration of the Aryan race; see Weindling, Health, Race and German Politics; Robert N. Proctor, The Nazi War on Cancer (Princeton: Princeton University Press, 200o). For the history of the discovery of the link between smoking and lung cancer generally, see Proctor, "History." 
Based on the available evidence the American Surgeon General ultimately concluded - in 1964 - that the link was "causal." At that time only two diseases could definitely be linked to smoking, namely lung cancer and COPD, but now we know that more than 30 diseases can be caused by smoking. Until recently it was believed that, as a result of the higher frequency of all these different diseases, the over-all mortality rate among life-long smokers is twice as high as that among life-long non-smokers. This would imply that half of all life-long smokers eventually die from the consequences of their tobacco use. However, recent studies have indicated that the relative risk is not 2 but 3 , which implies that two-thirds of life-long smokers are killed by their smoking habit. ${ }^{57}$

Anti-smoking action by public authorities, health care professionals, and voluntary organizations started in a health education mode, in which smokers were persuaded to stop smoking, and non-smokers were advised against taking up smoking. We now know that such campaigns have limited effectiveness, particularly among people in lower socioeconomic groups. Nevertheless, smoking already declined substantially (among men) in many countries in Northern and Western Europe between their peak rates in the 1950s/196os and the 1990s, when more systematic 'tobacco control' policies started to take shape. The current standard for tobacco control policies, the 'MPOWER' package of the World Health Organization, was defined in 2008, in order to help countries adhere to the 2003 Framework Convention on Tobacco Control. This is a convention to which almost 200 countries world-wide have signed up. ${ }^{58}$

Implementation of these measures has taken time in all European countries, but more so in some than in others. This is shown in regular monitoring reports which now cover the period 2004-2016. In general, the Nordic countries, the United Kingdom and Ireland have been most active, and far ahead of other countries in implementation of tobacco control measures, whereas the German-speaking countries of Western Europe (Germany, Austria, Switzerland, Luxembourg) lag surprisingly far behind. Southern European countries have also become quite active, and there is some recent catch-up in countries

57 The estimate of 2 comes from the famous British Doctors Study (Richard Doll et al., "Mortality in Relation to Smoking: 5o Years' Observations on Male British Doctors," British Medical Journal 328, no. 7455 (2004): 1519-528). The estimate of 3 comes from the American Cancer Prevention Studies (Michael J. Thun et al., "50-Year Trends in Smoking-Related Mortality in the United States," New England Journal of Medicine 368, no. 4 (2013): 351-64).

$5^{8}$ This package consists of: $\mathrm{M}=$ monitoring; $\mathrm{P}=$ protecting people from tobacco smoke; O: offering assistance to smokers to help them quit; W: warning about the dangers of tobacco use; $\mathrm{E}=$ enforcing bans on advertising, promotion and sponsorship; $\mathrm{R}$ = raising tobacco taxes. 
in South-eastern and Eastern Europe, which started their anti-smoking policies much later than most Western European countries. Despite considerable progress, and despite an increasingly important role of the European Union in harmonizing and strengthening tobacco control measures in its member states, there is still a huge gap between ideal and reality in many European countries. ${ }^{59}$

While the effectiveness of the tobacco control measures included in the MPOWER package has been demonstrated, it is unlikely that they have already contributed to the trends in lung cancer mortality seen in Figure 27. For example, most peaks in lung cancer mortality pre-date systematic tobacco control efforts by many years. However, there is a much shorter delay between smoking and some other health outcomes, such as ischaemic heart disease, and studies have shown that, for example, restrictions on smoking in public places have led to almost immediate reductions in the incidence of ischaemic heart disease. ${ }^{60}$

So what explains the patterns seen Figure 27? Northern and Western European countries had early smoking epidemics, both among men and among women. As these were also the European countries which were early modernizers in many other respects, the obvious explanation is that earlier uptake of smoking was a side-effect of their earlier economic, social and cultural modernization. This applies to men in these countries, and also to women, because these countries' higher levels of gender equality have facilitated an early takeup of smoking among women. ${ }^{61}$

These were also the countries where smoking started to decline early. Although part of this may reflect a decline of fashion, and a loss of the opportunities for 'social distinction' that smoking originally offered, this decline certainly occurred partly in response to the message that smoking was dangerous. Because the evidence was originally published in the United States and the United Kingdom, this message had little difficulty of reaching health care professionals and lay audiences in Northern and Western Europe.

59 I am referring to a series of reports in which European countries are ranked on the 'Tobacco Control Scale.' The most recent report was published in 2017 (Luk Joossens and Martin Raw, The Tobacco Control Scale 2016 in Europe (Brussels: Association of the European Cancer Leagues, 2017)).

6o For a general review of tobacco control efforts and their effect on smoking rates in Europe, see Laura Currie and Anna B. Gilmore, "Tobacco," in Successes and Failures of Health Policy in Europe, ed. Johan P. Mackenbach and Martin McKee (Maidenhead: Open University Press, 2013).

61 However, see Fred C. Pampel, "Cigarette Diffusion and Sex Differences in Smoking," Journal of Health and Social Behavior 42, no. 4 (2001): 388-404, for a different view. 
The later timing of the smoking epidemic in Southern, Central-Eastern and Eastern Europe has a largely similar, but symmetrically opposed explanation. The history of smoking in communist Europe, however, has some specific aspects that are worth briefly dwelling on. In most of these countries (with the exception of, e.g., Czechoslovakia and Hungary where men already took up smoking before World War II), the wide-spread uptake of smoking started when they were under communist regimes.

Although the wide-spread use of cigarettes is usually associated with commercial enterprise - and now with 'Big Tobacco', i.e., a handful of powerful multinational companies - cigarette production by state-run enterprises in communist countries was centrally planned to accommodate growing consumer demand. Cigarettes were cheap, smoking rates reached very high levels, and as we have seen in Figure 27, lung cancer mortality rates among men soared. Although anti-smoking campaigns were mounted, these were generally ineffective due to lack of trust in the government and lack of enforcement.

After the fall of communism, Western tobacco companies started aggressive marketing campaigns and made huge investments in building up a commercial tobacco sector in Central-eastern Europe and the former Soviet Union. This contributed to a stabilisation or even increase (creating a double peak) in smoking rates among men, and an increase in smoking rates among women. As a result, Russian, Belarussian, and Ukrainian men had some of the highest smoking rates of Europe in the 1990s and 2000s. ${ }^{62}$

Finally, when we step back from the tragic story of smoking and its health effects in the 2oth century, and try to place this in the broader perspective of the generally favourable trends in population health in Europe over several centuries, the obvious question to ask is: was this an 'accident of history'? Or is there a deeper link between the massive progress made in the 18th, 19th and

$62 \quad$ For trends in smoking in Central-eastern Europe and the Soviet Union, see Antonin K. Kubik et al., "Patterns of Cigarette Sales and Lung Cancer Mortality in Some Central and Eastern European Countries," Cancer 75, no. 10 (1995): 2452-46o; Richard Cooper, "Smoking in the Soviet Union," British Medical Journal 285, no. 6341 (1982): 549-51. For trends after 1990, and the role of the tobacco industry in promoting smoking in Central-eastern Europe and the former Soviet Union, see Witold Zatonski et al., "Tobacco Smoking in Countries of the European Union," Annals of Agricultural and Environmental Medicine 19, no. 2 (2012): 181-92; Bayard Roberts et al., "Changes in Smoking Prevalence in 8 Countries of the Former Soviet Union between 2001 and 2010," American Journal of Public Health 102, no. 7 (2012): 1320-328; Martin McKee et al., "Patterns of Smoking in Russia," Tobacco Control 7, no. 1 (1998): 22-6; Anna B. Gilmore and Martin McKee, "Tobacco and Transition: An Overview of Industry Investments, Impact and Influence in the Former Soviet Union," Tobacco Control 13, no. 2 (2004): 136-42. 
2oth centuries, and the setbacks caused by smoking, which made the latter more than a simple 'accident'?

As we have alluded to on several occasions above, the rise of smoking occurred in response to changes in economic and sociocultural conditions which were also involved in the improvements in European population health. As a luxury product, smoking became affordable when economic growth led to rising average incomes, and became a symbol of luxury (and many things else) with which people could distinguish themselves. Also, mass consumption was made possible by the industrial production and aggressive promotion of cigarettes - an economic mode that also brought many useful and even healthy products to consumers. Probably, smoking also satisfied psychological needs that arose with the profound social changes accompanying industrialization and urbanization.

While this suggests that the setbacks caused by smoking were certainly more than a simple 'accident', similarly fatal epidemics did not occur with other consumer products. Economic growth brought thousands of products (foods, drinks, household appliances, means of transport, ... ) within reach of European consumers, but none of these were as lethal as smoking. That widespread diffusion occurred with a fatal and addictive product like cigarettes, long before its pernicious effects were known, may therefore be seen as a tragic 'accident', but that sales continued after the early 1960 s was a crime.

\section{Liver Cirrhosis}

Alcohol consumption, particularly in higher doses, is a risk factor for many fatal and non-fatal health problems. Acute intoxication is a risk factor for injuries, both accidental and non-accidental, and for cardiovascular disease, whereas chronic heavy drinking is a risk factor for liver cirrhosis, various forms of cancer, and again cardiovascular disease. There is also a lot of psychiatric co-morbidity. ${ }^{63}$

A quick sketch of the history of alcohol-related health problems must start from the fact that beer was already brewed in prehistory, and wine was already made in the third millennium BCE. Despite the fact that the social and health problems associated with excessive drinking must also be very old, alcohol consumption is still widely accepted in most European cultures, probably because of its tension-reducing properties and indispensable role as a social lubricant.

63 For a recent overview of the many alcohol-related health problems, see World Health Organization, Global Status Report on Alcohol and Health 2018 (Geneva: WHO, 2018). 
As in the case of tobacco in a later period, mass production of alcoholic drinks like beer and spirits, together with the social changes associated with industrialization and urbanization, played an important role in the rise of drunkenness and other alcohol-related problems in the 18th and 19th centuries. For example, industrial production of distilled spirits led to a 'gin epidemic' in England in the 18th century, and the resulting social problems made the British government adopt increasingly strict 'Gin Acts' which limited points of sale and raised taxes, and in the end reduced consumption to lower levels.

Although epidemiological data for the 19th century are not available, anecdotal evidence testifies to the high prevalence of drunkenness in this period, particularly in the lower social classes. That alcohol-related problems were wide-spread is also suggested by the rise of the 'temperance movement'. This civic movement advocated government intervention against excessive alcohol consumption, sometimes successfully.

The 'temperance movement' was concentrated in English-speaking and Northern European countries, perhaps because of an underlying cultural link with Protestantism. It led to Prohibition of the production and sale of alcohol in the 1920 in the United States, and to less severe but ultimately more effective countermeasures in the 1920 and 1930 s in the Nordic countries. These have, however, more recently been relaxed as a result of integration into the European Union. ${ }^{64}$

Alcohol consumption declined - in the few North-western European countries for which we have data - since the last decades of the 19th century, probably in response to this increased regulation of alcohol sales and greater awareness of alcohol problems. It reached a low point in the 1950s, but then started to increase again, as a result of rising prosperity and relaxation of cultural restrictions on alcohol consumption (just like restraints on other forms of needsatisfying behaviour were loosened in this period). In Central-Eastern and Eastern Europe, wide-spread dissatisfaction and 'anomie' during the years of

64 On Britain's 18th century 'gin epidemic', see Jessica Warner et al., "Can Legislation Prevent Debauchery? Mother Gin and Public Health in 18th-Century England," American Journal of Public Health 91, no. 3 (2001): 375-84. For the history of the 'temperance movement' in Britain, see Brian Harrison, Drink and the Victorians (London: Faber and Faber, 1971). Differences between European countries in 'temperance cultures' have been analysed in Harry G. Levine, "Temperance Cultures: Alcohol as a Problem in Nordic and EnglishSpeaking Cultures," in The Nature of Alcohol and Drug Related Problems, ed. M. Lader, G. Edwards, and D.C. Drummond (New York, 1993). 
economic and political stagnation, and insecurity in the turbulent years after the end of communism, also played an important role. ${ }^{65}$

As in the case of smoking and the tobacco industry, the aggressive marketing strategies of the alcohol industry have also contributed to the persistence of problematically high levels of alcohol consumption, as well as to the rise in alcohol consumption in Central-eastern and Eastern Europe in the 1990s. ${ }^{66}$

The only alcohol-related health problem for which long-term trends can be assessed is mortality from liver cirrhosis (Figure 28). Possibly, liver cirrhosis mortality rose during the 19th century and then declined in the first half of the 2oth century, but only the latter trend can be seen in the few countries for which we have early data. Liver cirrhosis mortality increased sharply again since the 1950s, and then peaked at hugely varying points in time: in the 1970s in France, Spain, Italy and Sweden, in the 1990s in Hungary and Romania, and in the early 2000 s in the United Kingdom and Finland. ${ }^{67}$

The recently favourable trends in the Mediterranean countries have been attributed to a tightening of alcohol control policies, whereas the (until recently) unfavourable trends in Central-Eastern and Eastern Europe and in the United Kingdom have been attributed to a combination of increased affordability of alcohol and relaxation of alcohol control policies. ${ }^{68}$

Trends of mortality from other alcohol-related conditions than liver cirrhosis, for which comparable data are available over a more recent period only, have been studied less often. Within Europe, mortality from alcoholic psychosis, alcohol poisoning and alcohol dependence appears to have a different

65 For a more extensive discussion of the role of excessive alcohol consumption in the fluctuating mortality rates in Russia and other former parts of the Soviet Union, see Chapter 7 .

66 See, e.g., David H. Jernigan et al., "Alcohol Marketing and Youth Alcohol Consumption," Addiction 112, no. Suppl. 1 (2017): 7-20; David H. Jernigan, "The Global Alcohol Industry: An Overview," Addiction 104, no. Suppl. 1 (2009): 6-12.

67 On trends in liver cirrhosis mortality in Europe, see Cristina Bosetti et al., "Worldwide Mortality from Cirrhosis: An Update to 2002," Journal of Hepatology 46, no. 5 (2007): 82739; Witold A. Zatoński et al., "Liver Cirrhosis Mortality in Europe, with Special Attention to Central and Eastern Europe," European Addiction Research 16, no. 4 (2010): 193-201. The extraordinarily high peak of liver cirrhosis mortality in Hungary is partly an artefact. Because alcoholic liver cirrhosis was common in Hungary, it was easy to assign liver cirrhosis as a cause of death when the cause of death was not known with certainty. This practice changed in the 1990s, and this, together with the implementation of alcohol control policies, led to the reversal in the Hungarian liver cirrhosis trend seen in Figure 28; see Peter Józan, "Main Features of Epidemiological Development in Hungary after the Second World War," Hungarian Statistical Review 86, no. 12 (2008): 1-78.

68 Peter Anderson, "Alcohol," in Successes and Failures of Health Policy in Europe, ed. Johan P. Mackenbach and Martin McKee (Maidenhead: Open University Press, 2013). 
140

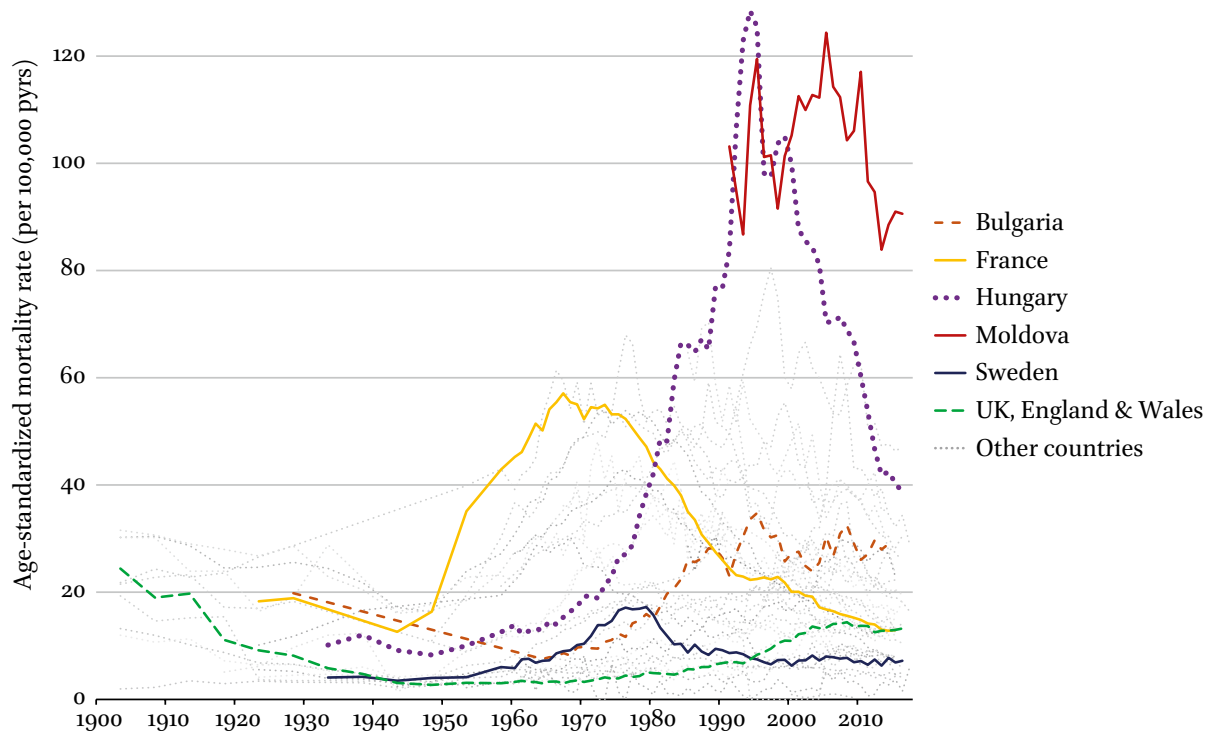

FIGURE 28 Trends in liver cirrhosis mortality in Europe, 1900-2015

Notes: Quinquennial data before 1960

SOURCE OF DATA: SEE SUPPL. TABLE 1

geographical pattern as compared to mortality from liver cirrhosis, with relatively high rates in the Nordic countries and in Eastern Europe. This has been attributed to a style of drinking characterized by non-daily drinking and frequent intoxication. Mortality from these intoxication-related conditions has been rising in many European countries, again pointing to the fact that alcohol-related health problems are far from being under control. ${ }^{69}$

\section{Dementia}

The declines in cause-specific mortality that we have seen in the previous sections have shifted the mean age of death upwards, and it is easy to understand that the share of diseases typical of very old age has increased. Some early authors, writing in the late 1970s when this had only just begun, even warned for a "pandemic of mental disorders and disabilities."

69 Mats Ramstedt, "Alcohol-Related Mortality in 15 European Countries in the Postwar Period," European Journal of Population/Revue Européenne de Démographie 18, no. 4 (2002): 307-23. 
As we have seen in Chapter 2, it is indeed true that, even after taking into account changes in age-distribution of the population, the share of some diseases of old age in total mortality has increased in many European countries. Mental and neurological diseases are among the very small number of causes of death for which trends in mortality have been upwards instead of downwards over the past decades. This should not be exaggerated, as the average share of these conditions in total mortality in Europe is still below $5 \%$, but it already exceeds $10 \%$ among women in several countries.

'Dementia', a group of brain diseases causing a decline in the ability to think and remember, is an important component of this broader category. It includes Alzheimer's disease (which accounts for more than half of all cases, and whose cause is unknown) and vascular dementia (which accounts for about a quarter of all cases, and which is caused by problems in the blood supply of the brain, such as small ischaemic strokes)(Plate 15).

Dementias are now among the top-10 (men) or even top-5 (women) of most frequent causes of death in several European countries, as a result of rapid rises in age-adjusted mortality. Mortality from motor neuron diseases (such as amyotrophic lateral sclerosis (ALS)) has also risen, but reports on trends in mortality from Parkinson's disease, multiple sclerosis and epilepsy have not shown consistent trends up or down. ${ }^{70}$

It is only since about 1980 that Alzheimer's disease and other dementias can clearly be identified in cause-of-death statistics (see Suppl. Figure 20). Since then, dementia mortality has increased strongly in many Northern and Western European countries, but remained low in South-eastern and Eastern Europe. Finland has extremely high, and continuously rising, levels of dementia mortality throughout the last decades: the difference now is more than $5^{0}$-fold between Finland and Bulgaria.

$70 \quad$ For warnings of a "pandemic of mental disorders and disabilities," see M. Kramer, "The Rising Pandemic of Mental Disorders and Associated Chronic Diseases and Disabilities," Acta Psychiatrica Scandinavica 62, no. Suppl. 285 (1980): 282-97; Ernest M. Gruenberg, "Epidemiology of Senile Dementia," Advances in Neurology 19 (1978): 437-57. The rise of dementia as a cause of death in Europe has been described in Vidar Hjellvik et al., "Dementia in the National Cause of Death Registry in Norway 1969-2010," Norsk Epidemiologi 22, no. 2 (2012): 217-24; Mackenbach et al., "Rise of Mortality." On trends in Parkinson's disease, multiple sclerosis, and epilepsy, see, e.g., Aidan Neligan et al., "Temporal Trends in the Mortality of People with Epilepsy," Epilepsia 51, no. 11 (2010): 2241-246; Michael J. Goldacre et al., "Trends in Death Certification for Multiple Sclerosis, Motor Neuron Disease, Parkinson's Disease and Epilepsy," Journal of Neurology 257, no. 5 (2010): 706-15; Colin W. Pritchard, David S. Baldwin, and Andrew G. Mayers, "Changing Patterns of Adult Neurological Deaths in the Major Western World Countries," Public Health 118, no. 4 (2004): 268-83. 


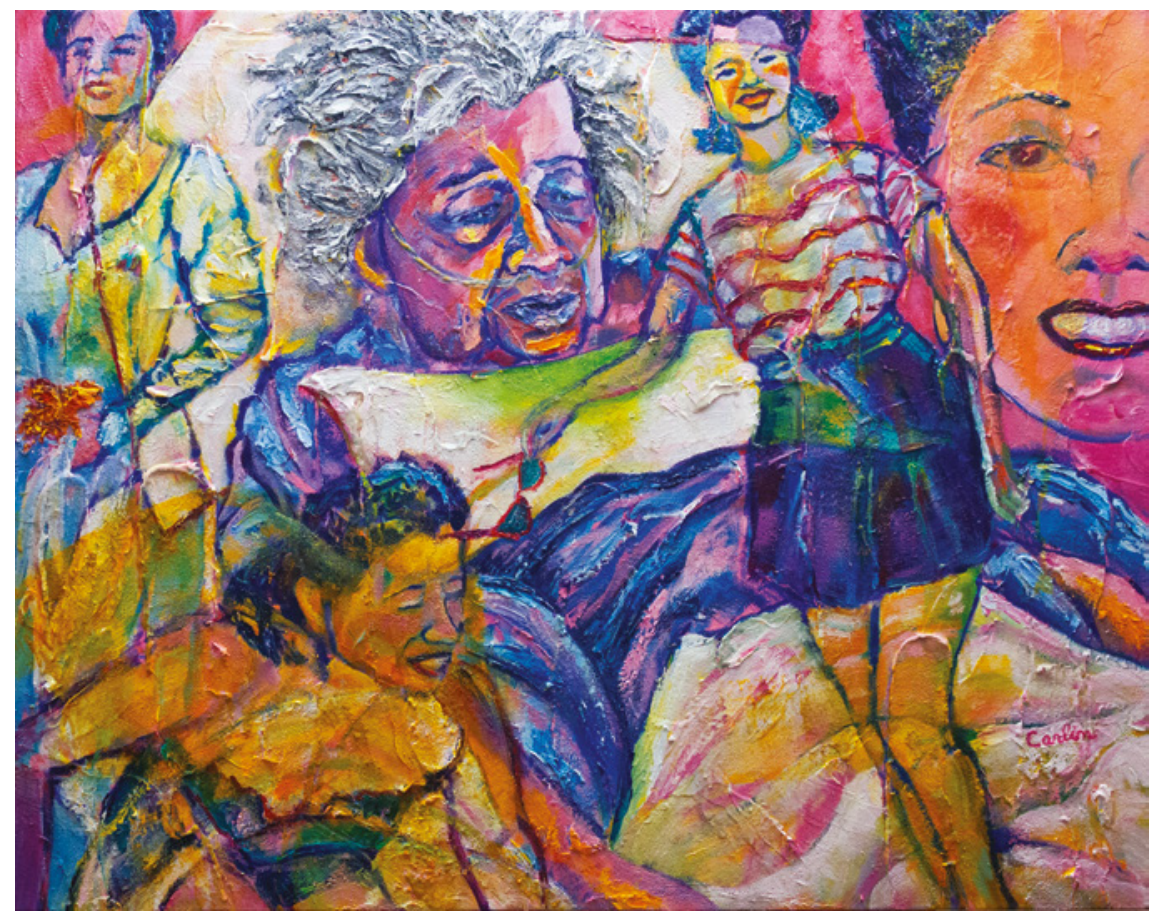

PLATE 15 "I was really something." Painting of a woman dying from Alzheimer's, 2015 According to the artist, Judith Carlin, this is a "painting of a woman dying from Alzheimer's remembering when she was young and beautiful and healthy." This tangled painting conveys the confusion of dementia patients - a confusion mirrored by modern societies' mixed feelings about the price we pay for our increased life expectancy

HTTPS://COMMONS.WIKIMEDIA.ORG/WIKI/CATEGORY:ALZHEIMER\% 27S_DISEASE\#/MEDIA/FILE:I_WAS_REALLY_SOMETHING.JPG (CC BY SA 4.0; ACCESSED 18/10/2019)

Are these striking trends and variations real, or an artefact of trends and variations in cause-of-death classification? Studies of time-trends in the incidence or prevalence of dementia over longer time-periods are scarce. A recent review suggests, however, that the age-adjusted incidence of dementia has been declining in several European countries, perhaps as a result of improvements in cardiovascular risk factors. The latter have been shown to increase the risk of both Alzheimer's and vascular dementia.

It is unlikely, therefore, that the increase in mortality from dementia represents an increase in incidence of the disease. As it is also unlikely that survival of patients with dementia has declined substantially - on the contrary: the 
evidence suggests that survival has been improving - this leaves improved recognition, diagnosis, certification and/or coding as the most likely explanation for the increase in mortality from dementia. ${ }^{71}$

This can be understood as follows. Dementia is less straightforward as a cause of death than, say, stroke or colorectal cancer. On the one hand, it does increase the risk of dying: the risk of dying among dementia patients is two or three times higher than that of people of the same age without dementia. On the other hand, the immediate cause of death of patients with dementia is often pneumonia or cardiovascular disease, and as a result dementia is not always mentioned on death certificates or coded as the underlying cause of death. ${ }^{72}$

This implies that there is a lot of scope for changes and variations in physicians' and statisticians' attitudes to affect the level of registered mortality from dementia. For example, recognition of dementia's role in causing patients' deaths is likely to have increased, particularly after other causes of death had gradually been eliminated. Nevertheless, even if the observed rise in dementia mortality is to a large extent artefactual, and if better recognition partly explains the higher rates in Northern and Western Europe, we are still left with a reality in which dementia has become a very important cause of death - and an even more important cause of disability.

\section{Depression}

If secular trends in dementia are difficult to measure, try mental illness! We are much better in monitoring health conditions that are on the decline, than in monitoring trends in diseases that are not, or not yet, declining. Like so many other things this is not a coincidence, because the existence of an effective monitoring machinery often reflects past attention to the problem by health care professionals and health policy-makers, and thus correlates with past investments in disease control. As an example of what we know and do not know about secular trends in mental illness, we will have a look at depression.

\footnotetext{
71 For a review of trends in incidence, prevalence and survival in dementia, see Martin Prince et al., "Recent Global Trends in the Prevalence and Incidence of Dementia, and Survival with Dementia," Alzheimer's Research \& Therapy 8, no. 1 (2016): 23.

72 For the risk of dying with dementia, see Uta Guehne, Steffi Riedel-Heller, and Matthias C. Angermeyer, "Mortality in Dementia," Neuroepidemiology 25, no. 3 (2005): 153-62, for the immediate causes of death in patients dying with dementia, see Janet Keene et al., "Death and Dementia," International Journal Geriatric Psychiatry 16, no. 10 (2001): 969-74, and for changes in coding, see Office for National Statistics, Results from the ICD-10 V2010 Bridge Coding Study, Statistical Bulletin, (Newport: Office for National Statistics, 2011).
} 
Depression, a disorder of mood of which the aetiology is not well understood, is one of the most common mental disorders, and even one of the most common health conditions over-all. According to the Global Burden of Disease study, depressive disorders are currently the number 3 most important cause of years-with-disability world-wide, after low back pain and headache. Apart from causing disability, depression is also an important risk factor for other health problems, including cardiovascular disease. Furthermore, about half of all suicides occur among people suffering from depression.

The cross-national World Mental Health Survey has recently collected data on the prevalence of 'major depressive disorder' (MDD), a sub-form of depression characterized by at least two weeks of serious symptoms in a row. The proportion of respondents who had experienced at least one such episode in the previous 12 months ranged between $3 \%$ in Italy and Germany and $6 \%$ in France. Although the measurement of depression was carefully harmonized between countries, we unfortunately do not know whether these differences are real or not. ${ }^{73}$

Awareness that depression is a major health problem is relatively recent, and only a few countries world-wide have data collection systems for monitoring trends in the incidence or prevalence of depression, e.g., in the form of periodic surveys using psychiatric screening instruments. In most cases, these have opened a 10 to 20 year time-window on recent trends in depression. This is hardly sufficient to qualify as a view on the history of depression, and even if we could extrapolate the results backwards in time this would not help much, because the trends found in these studies are inconsistent. Over the last decades, some European studies have found an increase in depression, others have found either a decrease or a stable rate. ${ }^{74}$

73 On the specific diagnostic criteria for Major Depressive Disorder, and the current understanding of its aetiology, see Christian Otte et al., "Major Depressive Disorder," Nature Reviews Disease primers 2 (2016): 16065. For the most recent Global Burden of Disease estimates, see GBD 2017 Collaborators, "Global, Regional, and National Incidence, Prevalence, and Years Lived." The comparative results of the World Mental Health Survey were summarized in Ronald C. Kessler and Evelyn J. Bromet, "The Epidemiology of Depression across Cultures," Annual Review of Public Health 34 (2013): 119-38.

74 Studies concluding on an increase include Cross-National Colaborative Group, "The Changing Rate of Major Depresion: Cross-National Comparisons," Journal of the American Medical Association 268 (1992): 3098-105; Hans W. Jeuring et al., "Secular Trends in the Prevalence of Major and Subthreshold Depression among 55-64-Year Olds over 20 Years," Psychological Medicine 48, no. 11 (2018): 1824-34; Eric Fombonne, "Increased Rates of Depression," Acta Psychiatrica Scandinavica 9o, no. 3 (1994): 145-56. Stable rates were found in Ron de Graaf et al., "Prevalence of Mental Disorders and Trends from 1996 to 2009," Social Psychiatry and Psychiatric Epidemiology 47, no. 2 (2012):203-13. A decline was found 


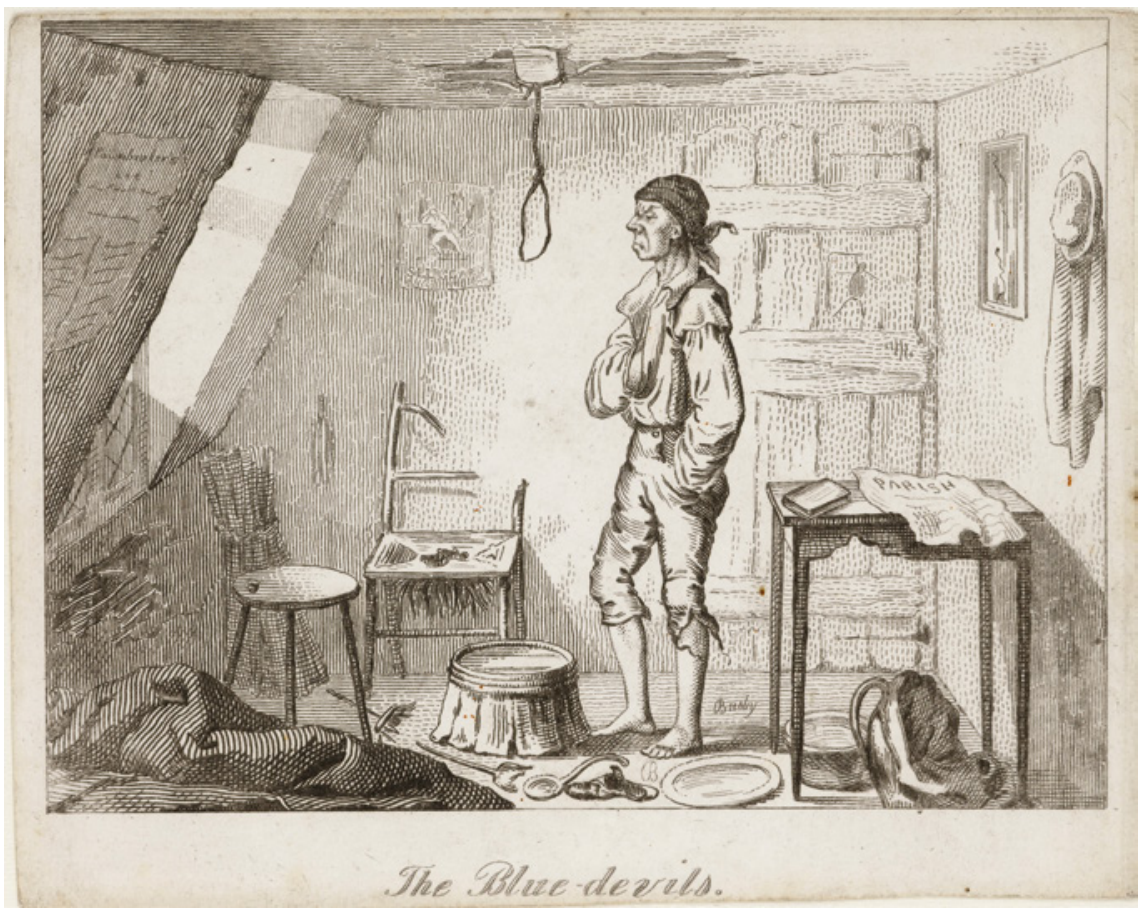

PLATE 16 A poor depressed man prepares to hang himself, 1826

A man suffering from the "blue devils," i.e., the demons that were believed to cause melancholia, looks at a noose attached to a roof-beam. On the table is a notice from the "Parish": possibly a tax-demand or a summons to the workhouse. This illustration shows that melancholia was not limited to the upper classes.

ETCHING BY T.L. BUSBY, CA. 1826. WELLCOME COLLECTION (CC BY)

Although it is impossible to compare depression's current prevalence with figures for previous historical periods, it is certain that depression is not a new disease (Plate 16). Patients with symptoms that we would now label 'depression' have been described in antiquity, but the term that has long been used to designate the condition was 'melancholia'. Very severe case histories have been published in the $17^{\text {th }}$ and 18 th centuries, perhaps suggesting that the disorder had become more common then, particularly among the educated classes.

Melancholia was a somewhat fluent concept, however, and even in the late 19th century, when modern psychiatry was born, classifications of different types of depression were very different from how the disorder and its sub-forms

in Cecilia Mattisson et al., "First Incidence Depression in the Lundby Study," Journal of Affective Disorders 87, no. 2-3 (2005): 151-6o. 
are understood today. The modern classification according to the Diagnostic and Statistical Manual of Mental Disorders (DSM) is entirely symptom-based. This avoids potentially false assumptions about aetiology, but has led to an increased recognition of milder forms of depression which qualify for treatment, mostly in the form of pharmaceutical drugs. ${ }^{75}$

For a naïve observer, it is difficult to understand that modern, prosperous societies have such high rates of depression. Important environmental correlates are childhood trauma, absence of a partner, experience of negative life events, financial or social problems, and low socioeconomic position. One would expect exposure to many of these environmental factors to have diminished over time, together with so many other unfavourable life circumstances. After all, in the 18th and 19th centuries, the risk of childhood neglect, loss of loved ones through death, and loss of shelter, work and income was far higher than in the early 21 st century. ${ }^{76}$

In order to explain this paradox we must therefore dig a bit deeper. Modern theories of depression, while still recognizing the importance of these environmental factors, have become considerably more complex, integrating biological, psychological and social factors, often in an evolutionary framework. It is now recognized that the nature of the stressor leading to depression is often more subtle than previously assumed: attachment loss, social defeat, loss of prestige, subordination, ... Vulnerable people may respond to such stressors by depression, which can be seen as an originally adaptive response inherited from humans' long evolution. When we lose out against others, depression makes us avoid further conflict, and when we are frustrated in our ambitions, depression protects us against continuing to pursue unrealistic goals.

These subtler forms of stress are probably not less common now than they were in previous centuries, which may help to explain the persistence of depression. For example, human competition is still overwhelmingly present, if not in the form of competition for material security then in the form of competition for prestige and being seen as attractive and useful to others. The same

75 A general history of the concept of depression through the ages, with an analysis of how changes in the understanding of the disorder translated into changes in classification, is Clark Lawlor, From Melancholia to Prozac (Oxford etc.: Oxford University Press 2012). Although the increased 'medicalization' of mild symptoms of depression may be criticized, it may also have contributed to the decline of suicide (see one of the following sections).

$7^{6}$ A classical study of the "social origins of depression" distinguished between provoking factors (such as the loss of one's job), symptom-formation factors (such as having experienced a previous episode) and vulnerability factors (such as early loss of one's mother); see George W. Brown and Tirril Harris, Social Origins of Depression (London: Tavistock Publications, 1978). 
applies to real and perceived inequalities in social rank, which translate into steep social inequalities in the prevalence of depression. ${ }^{77}$

A more general explanation, which does not only apply to depression but to many more forms of mental illness, is that during the second half of the 2oth century European societies have become 'knowledge economies', in which people no longer work with their hands but with their heads. Jobs in the expanding service sector require flexibility, self-management and adaptability, and a higher level of cognitive, social, and emotional skills than jobs in the shrinking agricultural or industrial sectors. In such a society mental ill-health is a serious barrier to individual success, and will therefore more readily be recognized and more often lead to seeking care. ${ }^{78}$

\section{Injuries}

\section{Road Traffic Injuries}

Prominent among the "man-made diseases" rising during Omran's epidemiologic transition were road traffic injuries. These indeed increased impressively during the decades preceding the publication of his landmark paper, mainly due to the rise of the automobile (Figure 29). ${ }^{79}$

77 For a recent integrative theory of depression, see Paul Gilbert, Depression: The Evolution of Powerlessness (London: Routledge, 1992). For evolutionary theories of depression, see Randolph M. Nesse, "Is Depression an Adaptation?," Archives of General Psychiatry 57, no. 1 (2000): 14-20; Paul Gilbert and Steven Allan, "The Role of Defeat and Entrapment (Arrested Flight) in Depression: An Exploration of an Evolutionary View," Psychological Medicine 28, no. 3 (1998): 585-98; for a critical assessment of these theories, see Edward H. Hagen, "Evolutionary Theories of Depression: A Critical Review," Canadian Journal of Psychiatry 56, no. 12 (2011): 716-26. A recent review of empirical evidence for the "social rank theory of depression" is Karen Wetherall, Kathryn A. Robb, and Rory C. O'Connor, "Social Rank Theory of Depression," Journal of Affective Disorders 246 (2019): 300-19.

78 The importance of "mental capital" has been argued in, e.g., John Beddington et al., "The Mental Wealth of Nations," Nature 455, no. 7216 (2008): 1057-06o. A thorough analysis of the changed nature of work and the importance of mental health for job performance in service economies can be found in Rifka Maria Weehuizen, "Mental Capital" (PhD Maastricht University, 2008).

79 Omran, "Epidemiologic Transition" lists road traffic injuries as "man-made," but many more factors are involved. "Road traffic injuries can be constructed as the result of individual misbehaviour, corporate irresponsibility, lack of administrative regulation or control, insufficient public maintenance and medical services, misguided transportation arrangements, [...] or just bad luck" (Iris Borowy, "Road Traffic Injuries: Social Change and Development," Medical History 57, no. 1 (2013): 108-38, p. 111). 


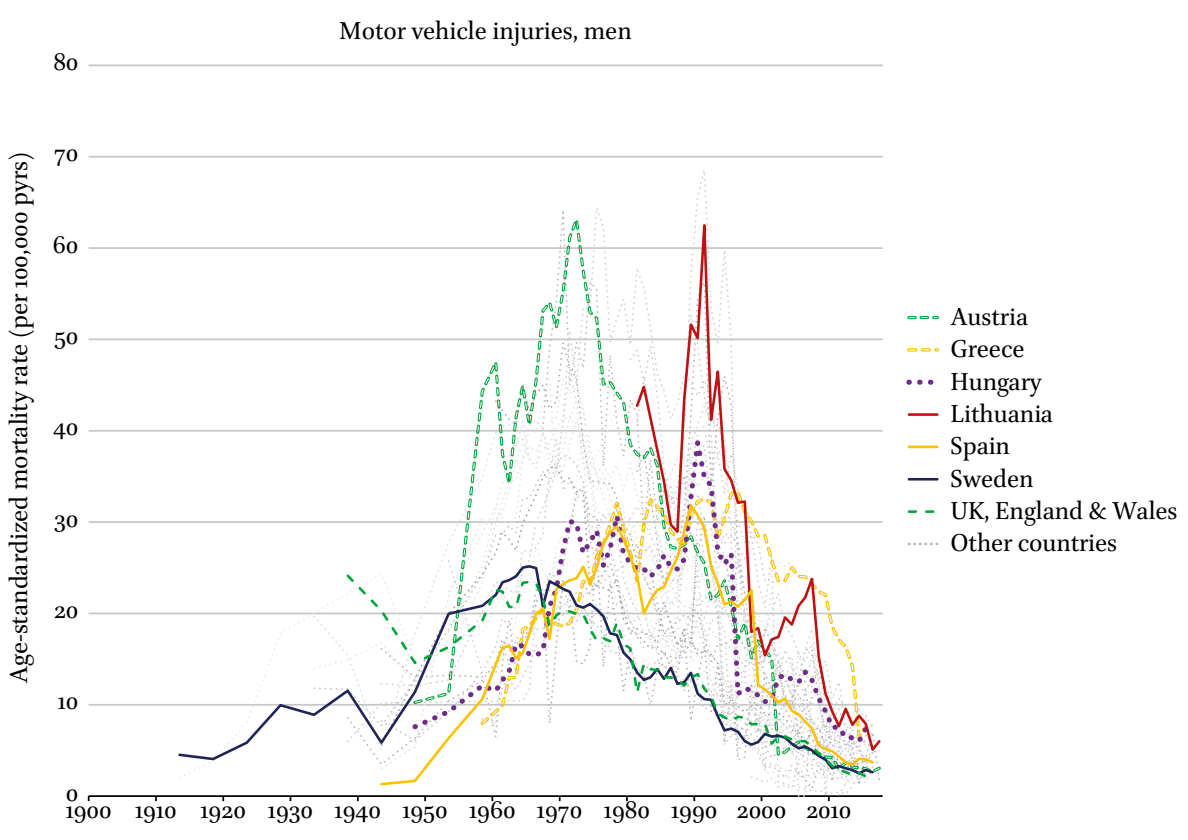

FIGURE 29 Trends in motor vehicle injury mortality in Europe, 1900-2015

Note: Mortality among motor vehicle occupants. Quinquennial data before 1960 SOURCE OF DATA: SEE SUPPL. TABLE 1

In Europe as a whole, deaths among road traffic participants occur predominantly among motor vehicle occupants $(53 \%)$, followed by pedestrians $(28 \%)$, riders of motorized two-wheelers $(8 \%)$, and cyclists $(2 \%)$. The distribution differs importantly between countries, depending on the most frequently used modes of transport. For example, in the Netherlands motor vehicle occupants and cyclists each account for about a third of all deaths. Nonetheless, because many deaths among pedestrians and cyclists are actually caused by collisions with motor vehicles, these, and particularly private passenger cars, are the main culprit everywhere. ${ }^{80}$

The modern automobile was developed in Europe, but first became part of everyday life in the United States during the early decades of the 2oth century, after cheaper versions like the Model-T Ford had been developed. In the 193os, Britain was the first European country where automobiles became more widespread, and other Western European countries followed during the post-War

8o World Health Organization, European Status Report on Road Safety (Copenhagen: wHO Regional Office for Europe, 2009). 
economic boom of the 1950s and 196os. Currently, the number of passenger cars per 1000 population is around 500 in Europe as a whole, and varies between 200 in Moldova and 700 in Iceland.

Behind the Iron Curtain the growth of car ownership followed more slowly, partly because the possession of a such a 'mobile private space' was seen to be in conflict with communist ideology. Yet, consumer demand ultimately trumped ideology, as illustrated by automobile production in the Soviet Union. After World War II car production in the Soviet Union grew rapidly, and while trucks were at first produced in much larger numbers than automobiles, passenger car production overtook truck production in the early 1970 s. $^{81}$

Like the cigarette, the automobile developed a highly positive image which increased its appeal to consumers. It was (and is) not only a miracle of technology, but also stood for a modern way of life characterized by freedom of movement and a high level of comfort. Although the automobile's image was tainted when air pollution became a major concern in the 1970s, and perhaps even more so when carbon dioxide emissions and climate change became an issue more recently, it is easy to understand why the automobile became so popular. It does not only satisfy modern man's seemingly insatiable desire for mobility, but is also a source of self-esteem. ${ }^{82}$

But, unfortunately, cars kill. They kill like horses killed their riders and bystanders in previous centuries, and like trains killed their passengers in the 19th century, but the death toll of cars in the 2oth century has been innumerably higher. The first deaths due to motor vehicles occurred in Britain in 1896, and as Britain was ahead of other European countries in its rate of motorization, motor vehicle injury mortality already reached high levels in the 1930s and peaked in the early 1940s. This was followed by a temporary decline in later years of World War II and the immediate post-war period, due to restrictions in fuel. Although there was a second peak in the early 196os, the debates sparked by the peak in the early 1940 led to an early emphasis on road traffic safety,

$81 \quad$ For the social history of the automobile, and how it became seen as a source of health damage, see Borowy, "Road Traffic Injuries." The history of automobile production and ownership in the Soviet Union has been documented in Lewis H. Siegelbaum, Cars for Comrades (Ithaca: Cornell University Press, 2008).

82 In a Scottish study, car ownership was found to be independently associated with longevity and better health - an effect that appeared to go partly through the higher self-esteem of car owners; see Sally Macintyre et al., "Do Housing Tenure and Car Access Predict Health Because They Are Simply Markers of Income or Self Esteem?," Journal of Epidemiology \& Community Health 52, no. 10 (1998): 657-64. Another study found that travelling by car conferred more self-esteem than travelling by public transport; see Anne Ellaway et al., "In the Driving Seat," Transportation Research Part F: Traffic Psychology and Behaviour 6 , no. 3 (2003): 217-31. 
which ensured that Britain never reached the high levels of motor vehicle injury mortality seen in other European countries. ${ }^{83}$

As Figure 29 shows, few other countries shared in the relatively favourable trends in Britain, which peaked at a rate about one third of that reached in some other European countries. Nevertheless, a similar pattern of 'rise-andfall' can be seen everywhere. Motor vehicle injury mortality peaked in the late 196os or 1970s in most countries in Northern and Western Europe, somewhat later in Southern Europe, and in the 1990s in most countries in Central-eastern and Eastern Europe.

In order to understand these trends, we need to keep in mind that, arithmetically, motor vehicle injury mortality equals injury incidence times case fatality, and that injury incidence equals injuries per kilometre travelled, times total kilometres travelled. Trends in mortality are thus determined by three different underlying trends: kilometres travelled, injuries per kilometre, and deaths per injury. Generally speaking, the rise in motor vehicle injury mortality seen before its peak is due to an increase in kilometres travelled, whereas the decline seen after the peak is due to a decline in both injuries per kilometre and deaths per injury. ${ }^{84}$

This decline in the likelihood of sustaining injury while travelling, and in the likelihood of dying after sustaining an injury, is a major achievement which can largely be attributed to the road safety policies which European countries (and the European Union) have undertaken. During the 1950s and 196os, the increasing toll of road traffic casualties came to be recognized as an 'epidemic' which needed to be approached like any other epidemic: based on a systematic analysis of its determinants and with an emphasis on 'passive safety measures', which did not necessitate active behaviour change in fallible traffic participants. ${ }^{85}$

83 The rise in road traffic injury mortality in Britain in 1939, 1940, and 1941 was partly due to the 'Black Out', i.e., restrictions on road lighting to protect Britain from German bombardments. This led to debates about whom to blame, but resulted in an early consensus that improving road safety was necessary; see Bill Luckin, "War on the Roads: Traffic Accidents and Social Tension in Britain, 1939-45," in Accidents in History, ed. R. Cooter and B. Luckin (Amsterdam \& Atlanta: Editions Rodopi, 1997).

84 For an example of an analysis along these lines, see Eduard F. van Beeck, C.W. Looman, and Johan P. Mackenbach, "Mortality Due to Unintentional Injuries in the Netherlands, 1950-1995," Public Health Reports 113, no. 5 (1998): 427-39. Although the decline of motor vehicle injury mortality in Western Europe is due to a decline of both the injury per kilometre and case fatality rate, the oil crisis of the early 1970 s helped by causing a temporary stabilization of the rise in kilometres travelled.

85 The history of the public health approach to road traffic injuries can be traced in Leslie G. Norman, Road Traffic Accidents: Epidemiology, Control, and Prevention (Geneva: World 
The development of effective policies to improve road traffic safety crystallized in a consensus that legislation, regulation, enforcement, engineering and education are all needed to create both safer road behaviour and improve the safety of vehicles and roads. Key areas for preventive interventions include controlling speed, stopping driving when under the influence of alcohol, enforcing use of safety equipment such as seat-belts, improving vehicle crash protection, and making roads safer for vehicles and vulnerable road users. Case fatality could be reduced by improving trauma care, e.g., by ensuring the quick arrival of emergency response teams and by optimizing the organization of trauma services. ${ }^{86}$

Implementation of these policies has been gradual, starting early in Britain, with Sweden and the Netherlands also in the forefront in the 196os and 1970s, and with countries in the rest of Europe following later, and sometimes much later. Road traffic safety policies have been a major determinant of trends in road traffic mortality, with declines in mortality often following implementation of one of the measures mentioned above. ${ }^{87}$

From the late 1960s onwards, many countries in Northern and Western Europe have continued to stack one road traffic safety policy upon another, which led to a spectacular decline in road traffic injury deaths, albeit it more so among motor vehicle occupants than among more vulnerable road users (Figure 29). In Southern European countries, which had experienced a somewhat delayed 'epidemic' of road traffic deaths, the turning-point came later. In the case of Spain, Portugal and Greece this was helped by adherence to the European Union. This required harmonization with European road traffic safety regulations, and provided road infrastructure investment funds.

Health Organization, 1962). This approach would later be elaborated in the so-called Haddon matrix; see William Haddon, "Options for the Prevention of Motor Vehicle Crash Injury," Israel Journal of Medical Sciences 16, no. 1 (1980): 45-65.

86 This consensus, as well as the underlying scientific evidence, has been summarized in Margie Peden et al., World Report on Road Traffic Injury Prevention (Geneva: World Health Organization, 2004) and in Dinesh Sethi, Injuries and Violence in Europe: Why They Matter and What Can Be Done (Copenhagen who Regional Office Europe, 2006).

87 Autonomous influences have probably also played a role in the decline of road traffic injury mortality, such as learning effects among car drivers, but these were enhanced by road safety education efforts. Similarly, improvements in car design have also been important, but stricter safety requirements imposed by the European Commission have accelerated that process. For implementation of road traffic safety policies across Europe, see Dovile Adminaite et al., Ranking EU Progress on Road Safety (Brussels: European Transport Safety Council, 2018). For their impact on road traffic mortality, see Dinesh Sethi and Franco Mitis, "Road Traffic Injuries," in Successes and Failures of Health Policy in Europe, ed. Johan P. Mackenbach and Martin McKee (Maidenhead: Open University Press). 
In Central-eastern, South-eastern and Eastern Europe, the collapse of the communist regimes was followed by a period of economic and social disruption, when both cars and alcohol flooded the market. This resulted in soaring rates of road traffic injury deaths. In the case of the (former) Soviet Union, cycles of increasing and decreasing alcohol consumption also strongly affected the trends. This is illustrated by the dip in motor vehicle injury mortality during Mikhail Gorbachev's anti-alcohol campaign in the mid-1980s, and several renewed rises and declines in the 1990s and early 2000s. The response to this calamity has been slow, but recent trends suggest that these countries are finally bringing this public health problem under control. ${ }^{88}$

These declines show that, although economic growth often goes together with rising road traffic injury mortality, declines can follow when effective countermeasures are taken - and these are of course more easily affordable with continued economic growth. Indeed, analyses of the world-wide association between national income and road traffic injury mortality show a striking reversal of the association between the two around the level that many Western European countries reached in the 1970s. When national income goes up, road traffic injury mortality rises too, but only up to a certain point after which it declines again. ${ }^{89}$

\section{Suicide}

The term 'suicide' was not used before the 165os, but taking one's own life has occurred at all times in human history. This is shown by the examples of depressive King Saul (ca. 1100 BCE), who killed himself after being defeated by the Philistines, and Stoic philosopher Seneca (ca. 4 BCE-65 CE), who saw suicide as a road to freedom and killed himself when he was accused of plotting against

88 For the slow policy response, see Martin McKee et al., "Health Policy-Making in Central and Eastern Europe: Lessons from the Inaction on Injuries?," Health Policy and Planning 15, no. 3 (2000): 263-69. On cycles in alcohol consumption and cycles in injury mortality in Russia, see Vladimir M. Shkolnikov, France Meslé, and Jacques Vallin, "Recent Trends in Life Expectancy and Causes of Death in Russia, 1970-1993," in Premature Death in the New Independent States, ed. J.A. Bobadilla, C.A. Costello, and F. Mitchell (Washington (DC): National Academies Press, 1997). For an analysis of recent anti-alcohol campaigns and decline of road traffic injury deaths in Russia, see William A. Pridemore et al., "The Impact of a National Alcohol Policy on Deaths Due to Transport Accidents in Russia," Addiction 108, no. 12 (2013): 2112-118.

89 Eduard F. van Beeck, Gerard J.J. Borsboom, and Johan P. Mackenbach, "Economic Development and Traffic Accident Mortality in the Industrialized World, 1962-1990," International Journal of Epidemiology 29, no. 3 (2000): 503-09; Elizabeth Kopits and Maureen Cropper, "Traffic Fatalities and Economic Growth," Accident Analysis and Prevention 37 (2005): 169-78. 
Roman emperor Nero. However, from the late 17th century the frequency of recorded suicides started to rise, first in England, later in other Western European countries, and still later in other parts of the subcontinent. ${ }^{90}$

National data on suicide only started to be collected in the 18th and early 19th centuries, and show a dramatically rising long-term trend, interrupted by temporary declines and epidemic peaks (Figure 30). Sweden was the first country to collect nation-wide statistics on suicide, to be followed by a number of other Northern and Western European countries. Despite strong fluctuations many of these countries experienced a large net increase in suicide rates until some point in the second half of the 2oth century, after which the trend reversed. ${ }^{91}$

Very high rates of suicide were temporarily recorded in the Nordic countries, for example by Denmark in the 1850 os and by Finland in the 1930s, and in German-speaking countries, for example by Austria and Germany in the 1930s. Although England's long-term trend of suicide is roughly similar to that of other Northern and Western European countries, its suicide rate never reached very high levels. The same is true for the Netherlands.

In Southern, Central-eastern, South-eastern and Eastern Europe, suicide rates generally started to rise later, i.e., in the second half of the 19th century or in the first decades of the 2oth century. Despite this general increase, suicide rates remained comparatively low in Italy, Spain, Portugal and Greece. On the other hand, suicide rates in Hungary, Russia and several other countries rose explosively during the 2oth century and reached extremely high levels before starting to decline more recently.

Covering a very long time-span, Figure 30 clearly brings out an over-all trend of 'rise-and-fall', but there were many temporary interruptions of the longterm trend, such as the peak in suicide mortality that several countries experienced in the 1930s. Below the surface of a single 'rise-and-fall', suicide in England has followed a trend of multiple smaller 'rises-and-falls'. For example, it

9o For the early history of suicide, see Georges Minois, Histoire du Suicide (Paris: Fayard, 1995). Based on the London Bills of Mortality, Barbagli, Farewell sees the rise of suicide starting in the 168 os. Both authors conclude that the rise in the frequency of recorded suicides reflected a real rise in the occurrence of suicide. The rise of suicide in England was well known among contemporaries elsewhere, who called it 'the English Malady'.

91 Currently, there are two main sources of information on suicide: cause-of-death statistics (based on registration by physicians) and judicial statistics (based on an evaluation of unnatural causes of death by the prosecutor or similar judicial authority). The reliability of suicide registration data is far from perfect, for example due to taboos on suicide leading to under-registration. Although the data in Figure 30 therefore need to be taken with a grain of salt, the larger changes and variations are likely to be valid. See Barbagli, Farewell, p. 313-14, for a short note on suicide registration. 


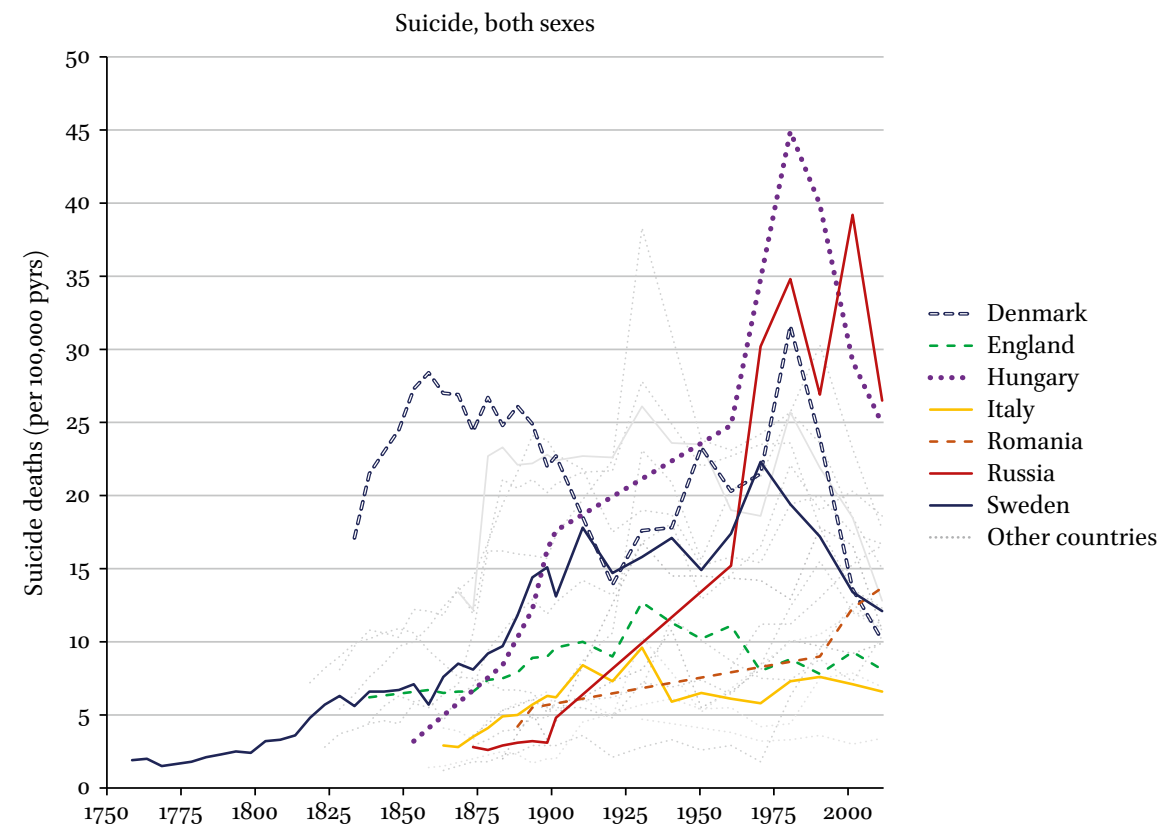

FIGURE 30 Trends in suicide in Europe, 1750-2010

Notes: Quinquennial or decadal data

SOURCE OF DATA: MARZIO BARBAGLI. FAREWELL TO THE WORLD: A HISTORY

OF SUICIDE. CAMBRIDGE \& MALDEN: POLITY PRESS, 2015, TABLE A.1-A.4

peaked in 1905, dipped during World War I, peaked again at a higher level during the Great Depression of the 1930s, dipped in World War II, rose again slightly in the 1950 s, etc. ${ }^{92}$

Detailed year-by-year analyses of single countries have shown that dramatic political events have sometimes been accompanied by equally dramatic rises of suicide mortality, as in the case of the defeat of France in the Franco-Prussian War in 1871, the occupation of the Netherlands by Germany in 1940, and the repression of the Hungarian uprising by the Soviet Union in 1956. On the other hand, as mentioned above for England, suicide rates often declined during

92 See Kyla Thomas and David Gunnell, "Suicide in England and Wales 1861-2007: A TimeTrends Analysis," International Journal of Epidemiology 39, no. 6 (2010): 1464-475 for an analysis of long-term trends in suicide in England and Wales. Figure 30 does not show that trends sometimes differ between men and women, and between younger and older people (see, e.g., David J. Gunnell et al., "Why Are Suicide Rates Rising in Young Men but Falling in the Elderly?," Social Science \& Medicine 57, no. 4 (2003): 595-611). 
war-time, particularly among men, perhaps as a result of strengthened national unity. ${ }^{93}$

What explains these secular trends? There is an enormous literature on the determinants of suicide as an individual act, but what primarily concerns us here are the determinants of suicide rates as a collective phenomenon. This perspective was first systematically elaborated by French sociologist Émile Durkheim (1858-1917), who argued that the frequency of suicide in a society reflects its degree of 'social integration'.

Social integration is dependent on the number and strength of ties that bind individuals to various social groups, and that protect against suicide by providing support and by regulating behaviour. According to Durkheim the suicide rate will be low when the degree of integration is high, whereas the suicide rate will rise during times of rapid social change. Then, ties are loosened and a situation of temporary or permanent 'anomie' arises, for example when people migrate from rural areas to larger cities. ${ }^{94}$

When compared with the long-term trends of suicide in Europe (Figure 30), Durkheim's theory does indeed appear to have some explanatory power. As mentioned above, the decline of suicide in war may be an effect of increased social integration. Loss of social integration, as a result of industrialization and urbanization, can probably explain some of the rise of suicide in Western and Northern Europe during the 19th century, and in other parts of Europe during the 2oth century. ${ }^{95}$

The further rise of suicide in communist countries after World War II may be due to a further increase in 'anomie' as a result of profound societal changes, combined with a rise of excessive alcohol consumption which reduces behavioural inhibition and thereby lowers the threshold for committing

93 On the effects of political events and wars on suicide, see Chesnais, Histoire and Barbagli, Farewell. Cornelis S. Kruijt, Zelfmoord: Statistisch-Sociologische Verkenningen (Assen Van Gorcum, 1960), Chapter 4 analysed the effect of the German occupation on suicide in the Netherlands.

94 Durkheim's study was published in 1897 , and reflected the increasing concern all around Western Europe with rising suicide rates (Emile Durkheim, Suicide: Étude de Sociologie (Paris: Félix Alcan, 1897)). Durkheim noted that the (seemingly) individual act of suicide gave rise to remarkably stable rates of suicide at the aggregate level. While this is true in the short run, Figure 30 shows that this is not really true in the longer run. For a modern re-think of Durkheim's 'social integration', see Lisa F. Berkman et al., "From Social Integration to Health: Durkheim in the New Millennium," Social Science \& Medicine 51, no. 6 (2000): 843-57.

95 The rise of suicide in Denmark and Norway in the first half of the 19th century is not due to industrialization and urbanization, but to brutal agrarian reforms; see Kruijt, Zelfmoord, p. 29. 
suicide. After the collapse of the Soviet Union in 1991, rates of suicide rose even further, partly as a result of the severe economic crisis that accompanied the rapid transformation of a communist into a capitalist society. ${ }^{96}$

But loss of social integration is certainly not the whole story. The rise of suicide started long before the take-off of industrialization and urbanization: as we have seen above, it started in England as early as the 1680 s and in Sweden as early as the late 18 th century. The most likely explanation, extensively documented in contemporary writings and changes in formal procedures surrounding suicide, is that suicide started to rise as a result of cultural changes. In the Middle Ages and early modern period, suicide used to be strictly forbidden and severely sanctioned for religious reasons, but this changed under the influence of the Enlightenment and the gradual recognition that suicidal tendencies often reflected mental disorders such as melancholia. ${ }^{97}$

That loss of social integration is not the only important determinant of long-term trends in suicide is also clear from the rise of suicide during economic crises. Suicide rose not only during the economic crisis in former communist countries during the 1990s, but during all the major economic crises of the 2oth century, including the Great Depression after the 1929 financial crisis, and the Great Recession after the 2008 financial crisis. This rise occurs particularly among young and middle-aged men and among the unemployed, and is likely due to despair among those who lose their jobs, incomes, feelings of selfworth, etc. Although loss of social integration may also play a role, this is only one of the social-psychological mechanisms involved in the rise of suicide during unemployment. ${ }^{98}$

While the factors described so far - social integration, political upheavals, cultural restrictions, economic despair - all to a greater or lesser extent reflect the nature of a society, two other factors have a more incidental character, but can nevertheless profoundly modify the relationship between the nature of society and the frequency of suicide.

The first of these is access to the means of committing suicide. A wellknown example is the declining incidence of suicide by gassing in the 196os in

96 See Barbagli, Farewell and Chesnais, Histoire for an interpretation of long-term trends in suicide in Central-eastern and Eastern Europe.

97 These cultural changes have been documented in Minois, Histoire and Barbagli, Farewell. On the medicalization of suicide and its role in making suicide acceptable, see Michael MacDonald, "The Medicalization of Suicide in England: Laymen, Physicians, and Cultural Change, 1500-1870," Milbank Quarterly 67, no. Suppl. 1 (1989): 69-91.

98 Barbagli, Farewell; Chesnais, Histoire. For an analysis of the effects of the 2008 financial crisis, see Shu-Sen Chang et al., "Impact of 2008 Global Economic Crisis on Suicide: Time Trend Study in 54 Countries," British Medical Journal 347 (2013): f5239. 
England, when domestic gas produced from coal, which had a high content in carbon monoxide, was replaced by non-poisonous natural gas. As this was not compensated by a rise in other methods of suicide, total incidence of suicide also declined, illustrating that a simple change in the means available for suicide can fundamentally affect the frequency with which people kill themselves. ${ }^{99}$

The second factor that may modify the relationship between society's underlying tendency for suicide and the actual rate at which suicide occurs, is the availability of effective mental health care. The recent decline of suicide that has been observed across Europe (Figure 30) is unlikely to be explained by increased social integration. It is probably at least partly attributable to increased access to mental health care, increased use of anti-depressants, increased awareness of the risk of suicide among mental health care professionals, more wide-spread implementation of suicide prevention programs, and more effective treatment of pain from somatic conditions. ${ }^{100}$

Clearly then, suicide trends do not have a simple explanation. The rise of suicide appears to be explained by a combination of economic, sociocultural and psychological 'modernization' of society, but the influence of these societal factors is strongly modified by other factors. This also implies that suicide is not a reliable indicator of population mental health. ${ }^{101}$

\section{A New Plague}

\section{AIDS}

AIDS (Acquired Immuno-Deficiency Syndrome) came as a shock. In the 1960s and 1970s, large-scale mortality from infectious diseases seemed to have become a thing of the past, at least in high-income countries, and then a new

99 Norman Kreitman, “The Coal Gas Story. United Kingdom Suicide Rates, 1960-71," Journal of Epidemiology \& Community Health 30, no. 2 (1976): 86-93; Thomas and Gunnell, "Suicide in England and Wales."

100 For a general analysis, see Barbagli, Farewell, For the role of anti-depressants, see Svein Reseland, Isabelle Bray, and David Gunnell, "Relationship between Antidepressant Sales and Secular Trends in Suicide Rates in the Nordic Countries," British Journal of Psychiatry 188, no. 4 (2006): $354-58$. For the role of suicide prevention programs, see Bruce Singh and Rachel Jenkins, "Suicide Prevention Strategies: An International Perspective," International Review of Psychiatry 12, no. 1 (2000): 7-14.

101 This is also clear from the fact that 'parasuicide' ('unsuccessful' suicide attempts), while being much more frequent than suicide, has a completely different epidemiology; see David J. Gunnell, "The Epidemiology of Suicide," International Review of Psychiatry 12, no. $1(2000): 21-6$. 
epidemic disease arrived which threatened to become as deadly as the plague. And so it did - world-wide, the annual number of AIDS deaths currently is around 1 million, and the total death toll since the early 1980 s is around 35 million. ${ }^{102}$

Most of these deaths have occurred in Sub-Saharan Africa, and the epidemic has been less severe in Europe, but it still caused large numbers of deaths, in a curiously bimodal pattern (Figure 31). Trends in mortality can be followed from 1983, when the International Classification of Diseases was provisionally adapted to include this new disease amongst its codes. Many countries in Northern, Western, and Southern Europe had a peak of AIDS mortality in the early 1990s, but there were enormous differences in peak level. Spain and Portugal stand out with much higher peak levels than other countries. Many countries in Eastern Europe had a high peak of AIDS mortality around 2010, and in some countries, such as Russia, mortality is still increasing as judged on the basis of the latest available data.

The first cases of AIDS were reported in 1981 in the United States, but it soon turned out that the first European cases had occurred at about the same time, i.e., in 1979 or 1980. Later, studies of stored blood and tissue samples uncovered many earlier cases, that had already occurred in the 1940s and 1950s but had gone unrecognized. It is now thought that sporadic cases of AIDS have probably occurred in Africa since the beginning of the 2oth century, and that the disease was already wide-spread in parts of Africa during the 1970 and 1980 . ${ }^{103}$

The infectious agent that caused AIDS was discovered very rapidly, in 1983, by teams of American and French researchers. The Human Immunodeficiency Virus (HIV) comes in two types, HIV-1 and HIV-2, and both probably evolved

102 Statistics on HIV and AIDS are collected and published by UNAIDS (http://www.unaids .org/en/resources/fact-sheet), the World Health Organization (https:/www.who.int/gho/ hiv/en/), and the European Centre for Disease Prevention and Control European Centers for Disease Control, HIV/AIDS Surveillance in Europe: 2017 Data (Copenhagen: World Health Organization, 2018).

103 The first historian to publish a detailed and well-informed history of AIDs (already in 1989!) was Mirko Grmek; see Mirko D. Grmek, Histoire du Sida (Paris: Payot, 1989). Since then, many more pieces of evidence on the origins and early spread of AIDS have surfaced. For an overview of the history of AIDS in Africa, see John Iliffe, The African AIDS Epidemic: A History (Athens: Ohio University Press, 2006). Genetic analyses of the virus as found in stored blood samples of early patients suggest that the epidemic spread from Africa to the Caribbean in the 196os, and from there to (first) New York and (then) San Francisco in the 1970s; see Michael Worobey et al., "1970s and 'Patient o' HIV-1 Genomes Illuminate Early HIV/AIDS History in North America," Nature 539, no. 7627 (2016): 98-101. 


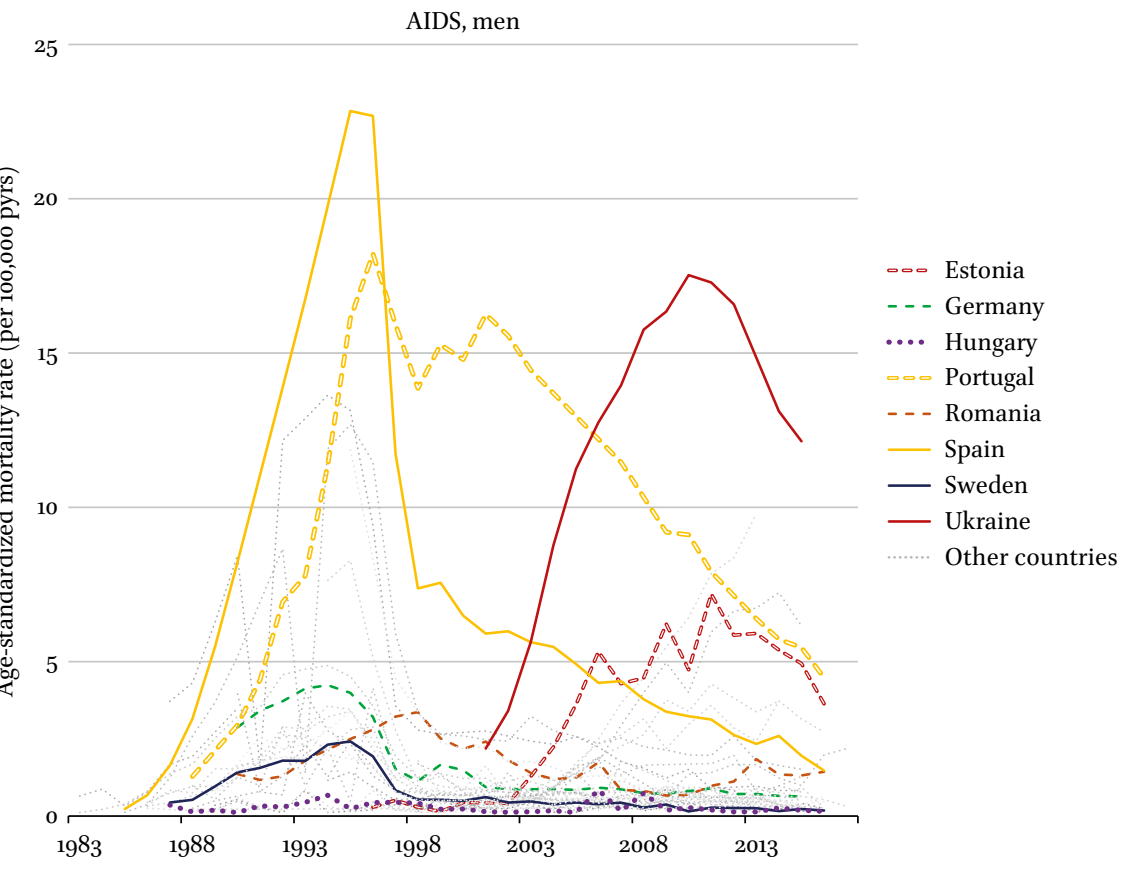

FIGURE 31 Trends in AIDS mortality in Europe, 1983-2017 SOURCE OF DATA: SEE SUPPL. TABLE 1

from similar viruses in chimpanzees and monkeys in Africa, from which they transferred to humans in the early 2oth century. HIV-infection did not spread widely beyond Africa at the time, and gave rise to a world-wide epidemic only when conditions arose that promoted its spread, at first within the global gay community.

Increased tourism and international travel were one important condition fostering the spread of HIV. Sexual liberation and gay emancipation were another, intensifying sexual relations and increasing the number of sexual contacts. Medical developments also played a role: the increased use of blood products made it possible for the virus to spread to patients needing blood transfusions, and the wide availability of disposable injection needles made it possible for the virus to spread to intravenous drug users.

The world-wide AIDS epidemic started among gay men, and HIV transmission between men-who-have-sex-with-men still accounts for $21 \%$ of all cases in Europe as a whole. With $40 \%$ this is still the most important mode of transmission in Western Europe. Nevertheless, over time other modes of HIV transmission have become more important, and in Europe as a whole the most 
common mode now is heterosexual sex (49\%), whereas intravenous drug use accounts for $13 \%$ and transmission between mother and child for $1 \% .{ }^{104}$

Before the advent of effective drug treatment, the disease itself was almost as frightening as plague, cholera and tuberculosis had been in the past. HIV infection interferes with the immune system, increasing the risk of tuberculosis and other infections (such as Pneumocystis carinii pneumonia), and increasing the risk of tumours that are extremely rare in people without HIV infection (such as Kaposi's sarcoma). When these complications occurred, AIDS used to be highly fatal.

However, the public response to AIDS in North America and Western Europe was extremely rapid. American and European governments made large investments in research, and these soon paid off in the development of effective drug treatment. The first effective drug, zidovudine (AZT), was approved by the American Federal Drug Administration in 1987, but did only suppress the virus for a relatively short time. The real breakthrough was the introduction in 1996 of highly active antiretroviral therapy (HAART), a combination of different antiviral agents. These treatments have drastically reduced case fatality, and contributed to the precipitous decline of AIDS mortality in the second half of the 1990s. ${ }^{105}$

Simultaneously, effective prevention strategies were developed, at first focusing on the promotion of 'safe sex' practices among gay men. Because homosexuality was not yet accepted in all sectors of society, a subtle approach was needed, and there were large differences between European countries in the extent to which they were able to develop and implement prevention programs that were both effective and acceptable. Countries in Northern and Western Europe were generally much more successful than the culturally more conservative countries in the rest of Europe. ${ }^{106}$

104 European Centers for Disease Control, HIV/AIDS Surveillance.

105 Yet, people in Europe still die from AIDs in large numbers; see R.D. Simmons et al., "TenYear Mortality Trends among Persons Diagnosed with HIV Infection in England and Wales," HIV Medicine 14, no. 10 (2013): 596-604; Valerie Delpech and J. Lundgren, "Death from AIDS Is Preventable, So Why Are People Still Dying of AIDs in Europe?," Eurosurveillance 19, no. 47 (2014): 20973.

106 Virginia Berridge and Philip Strong, eds., AIDS and Contemporary History (Cambridge etc.: Cambridge University Press, 1993); Virginia Berridge, "AIDS in the UK: The Making of Policy, 1981-1994," in Sex, State and Society: Comparative Perspectives on the History of Sexuality, ed. Lars-Göran Tedebrand (Umeå: Nyheternas tryckeri, 1996); Bernd Rechel, "HIV/ AIDs in the Countries of the Former Soviet Union," Central European Journal of Public Health 18, no. 2 (2010): 110-15; Carlos Alvarez-Dardet and I Hernandez Aguado, "AIDS in Spain: Lessons Learned from a Public Health Disaster," Journal of Epidemiology and Community Health 48, no. 4 (1994): 331-32. 
It is not easy to assess the effects of these prevention programs, because national trends in incidence of HIV infection can only be followed from a relatively recent point in time onwards, after diagnosis of HIV diagnosis had become notifiable or other registration systems had been installed. Since 2008, the incidence of HIV infection still appears to be increasing in Europe as a whole, but to be declining in several Western European countries, which may partly reflect the impact of prevention programs. ${ }^{107}$

While the epidemic rise of HIV infection, and then the impact of treatment and prevention, help to understand the general pattern of 'rise-and-fall' of AIDS mortality, it does not immediately explain the enormous variations between countries. One important clue is that the highest peaks of AIDS mortality occurred in countries in which the virus was spread by intravenous drug users, from whom it also spread into the heterosexual population. This applies to Spain and Portugal, and also to Eastern European countries.

Intravenous drug users are a group that is very difficult to reach by prevention campaigns, including secondary prevention aimed at early detection of HIV-infection. As a result HIV-infection is often detected at a late stage in which treatment is less effective. The massive epidemics of HIV infection and AIDS mortality seen in Spain and Portugal are due to the fact that, due to cultural and religious conservatism, harm reduction strategies (methadone treatment, needle exchange, ...) were unacceptable when the epidemic broke out. ${ }^{108}$

Similar explanations apply to Eastern European countries where massive epidemics of HIV infection and AIDS mortality have occurred: Estonia, Ukraine, Russia, Moldova. Intravenous drug use generally arrived in these countries after the collapse of the Soviet Union, coinciding with the economic and social crisis during the 1990s. In addition to the cultural barriers just mentioned,

107 European Centers for Disease Control, HIV/AIDS Surveillance.

108 For the same reasons, campaigns to promote 'safe sex' among homosexuals were also less feasible. On Spain, see Alvarez-Dardet and Aguado, "AIDs in Spain"; Marta Torrens et al., "Methadone Maintenance Treatment in Spain," Bulletin of the World Health Organization 91 (2013): 136-41. The introduction of harm reduction strategies among intravenous drug users was delayed in Spain, but the AIDS epidemic caused a shift in attitudes in the 199os, which made methadone maintenance treatment more acceptable; see Torrens et al., "Methadone." On Portugal, see Paula Santana and Helena Nogueira, "AIDs/HIV Mortality in Portugal in the 9os," Revista Portuguesa de Saúde Pública, no. 1 (2005):57-68. On Greece, see Anastasia Pharris et al., "Human Immunodeficiency Virus in Injecting Drug Users in Europe," Eurosurveillance 16, no. 48 (2011): 20032. 
a failure of national health systems to cope with such an unusual threat also played a role. ${ }^{109}$

109 On AIDS in all countries of the former Soviet Union as a whole, see Rechel, "HIV/AIDS in the Countries of the Former Soviet Union." On Russia specifically, see Elena TkatchenkoSchmidt et al., "Why Do Health Systems Matter?," Health Policy and Planning 25, no. 4 (2010): 283-91. On Estonia specifically, see Kaja-Triin Laisaar et al., "Estonia at the Threshold of the Fourth Decade of the AIDs Era in Europe," AIDS Research and Human Retroviruses 27, no. 8 (2011): 841-51. 